\title{
A Psychological Theory of Reasoning as Logical Evidence-a Piagetian Perspective
}

\section{Abstract}

Many contemporary logicians acknowledge a plurality of logical theories and accept that theory choice is in part motivated by logical evidence. However, just as there is no agreement on logical theories, there is also no consensus on what constitutes logical evidence. In this paper, I outline Jean Piaget's psychological theory of reasoning and show how he used it to diagnose and solve one of the paradoxes of material implication. I assess Piaget's use of psychology as a source of evidence for logical theory in light of reservations raised by psychologism, and I highlight some ramifications for exceptionalism and anti-exceptionalism about logic by considering his use of psychology as logical evidence in the framework of genetic epistemology, Piaget's research programme. I conclude that Piaget's psychological theory of reasoning not only plausibly serves as a source of evidence for logical theory but also makes a strong case for anti-exceptionalism about logic.

\section{Keywords}

Logic; logical evidence; exceptionalism, anti-exceptionalism; operations of thought; psychologism; constructivism; genetic epistemology.

\section{Introduction: Logic and Psychology}

Traditionally, logic enjoyed an exceptional status. On the one hand, it was thought to be elementary, i.e., it looks out for the rationality of the sciences, mathematics, jurisprudence, etc., but cannot look to these to look out for itself. On the other hand, its truths were thought to have special properties - a priori, necessary, formal, general, etc. - and thus constitute an exceptional kind of knowledge. Opinion was divided over the source of such truths. Given their exceptional properties, knowledge of them was thought to be acquired without the senses, and rationalists conjectured a special mental faculty for grasping them. Reluctant to acknowledge any source of knowledge other than the senses, empiricists, on the other hand, either argued that sense experience was ultimately the source of logical truths or accepted that they are a priori but denied the existence of a special mental faculty for grasping them. The latter accounted for the a priori nature of logical truths by appealing to analysis of the meaning of concepts involved in statements. (Hjortland 2019, sec. 2; Martin and Hjortland 2021, sec. 1)

Until the middle of $19^{\text {th }}$ century, syllogistic logic in the Aristotelian tradition was still the dominant paradigm. Due to the work of logicians like George Boole, Augustus De Morgan, William Hamilton, Bernard Bolzano and Franz Brentano, however, syllogistic's grip on the mind was already slipping as Frege, Russell, and Whitehead replaced it by a new paradigm (henceforth CL for Classical Logic). For some time after, logic was equated with first-order logic, and it has remained the paragon to this day (Jaakko and Sandu 2007, sec. 10). Nevertheless, logical pluralism is now accepted (e.g., Russell 2019; Restall and Beall 2000; Restall and Beall 2001), and, when asked what logic is, modern logicians, in contrast to their 
pre- $20^{\text {th }}$-centrury colleagues, are faced with an embarrassment of logical riches from which to choose (Jaakko and Sandu 2007, 13; Jacquette 2007, 3).

In Jacquette's (2007, 3-4) opinion, at least three factors are key to understanding the historical development of a plurality of logics: developments in $19^{\text {th }}$-century mathematics, and the development of modal and relevance logics. Mathematics was already the source of inspiration for the vanguard of logicians freeing deductive thought from the shackles of syllogistic, and Jacquette suggests that developments in mathematics also paved the way for the development of modal and relevance logics. In particular, the discovery of non-Euclidean geometries in the first half of the $19^{\text {th }}$ century and the astonishing contribution they made to the advancement of physics precipitated 'rethinking the concept of a formal system as any self-consistent axiom system whose implications can be rigorously investigated' and encouraged logicians to experiment analogously with different systems of logic (Jacquette $2007,4)$. According to Read $(1995,61)$, '[1] ogic was seen as a set of truths, to be derived from self-evident axioms by two or three rules of inference' already in the classical paradigm, and he regards this as a consequence of logical truth taking centre stage under the preeminence of the axiomatic method (Read 1995, 62).

Whilst the axiomatic method provides a plausible explanation for the means, it does not wholly explain the motivation for developing new logical theories ${ }^{1}$. Whilst an element of play was surely involved, the development of many nonclassical logics were internally and externally motivated. Foundational concerns in mathematics inspired the development of CL, and logicians wishing to widen logic's scope adapted it to accommodate new subject matter such as quantum physics, constructivist philosophy of mathematics, theoretical considerations of meaning, natural-language use, etc., whereby anomalies, paradoxes especially, played a substantial role. (Haack 1978, chap. 9; Martin and Hjortland 2021, sec. 4)

Hand-in-hand with the burgeoning of logical theories, logicians began to tap new sources of evidence for their theories besides those traditionally accepted. Studies of contemporary practice show that logicians are more liberal in their interpretation of logical evidence. For example, Hjortland and Martin (Hjortland 2017, 644; Hjortland 2019; Martin 2020) list theories of truth, mathematical theories and practice, quantum physics, psychology of reasoning, epistemic norms of rationality, vagueness, semantic paradoxes and set theory, in addition to empirical findings, and natural-language use. Interestingly, Hjortland mentions psychology of reasoning in (Hjortland 2017, 644), but it is not listed in (Martin and Hjortland 2021). Although no claim is made that the lists are exhaustive, the omission of psychology as a possible source is no mere oversight. Hjortland $(2019,255)$ holds that it is better to distinguish logic from reasoning; he also advocates a typical division of labour, according to which psychology is appropriate for investigating how we reason while the validity of inferences is the subject matter of logical theories. Martin (Martin 2020), on the other hand, derives what constitutes logical evidence from the practice of logicians.

\footnotetext{
${ }^{1}$ Following Hjortland (2019, sec. 2; see also 2017, secs. 3 \& 4), I will use 'logical theory' to denote an account of logical properties such as validity, consistency, formality, truth preservation, provability, etc.

However, I will continue to use 'logic' in the singular rather than the plural to refer to logical theories in a generic way despite logical pluralism.
} 
The ambivalence regarding psychology of reasoning as a source of logical evidence and advocacy of a strict division of labour are symptomatic of modern attitudes towards logic and psychology. Traditionally, appeal to psychology was often made to shed light on philosophical inquiry, especially inquiries into the workings of the mind. Since thoughts are mental phenomena and truth is a property of certain types of judgements, it seemed quite natural for psychologically orientated philosophers and experimental psychologist alike to consider logic to be within their purview. However, psychology as an experimental science began to emancipate itself from philosophy at the end of the $19^{\text {th }}$ century, and there was a psychological resurgence in philosophy (George 1997; Kusch 2006; Kusch 2015a; Kusch 2015b). As psychology reached its imperialist heights, Frege saw the need to limit psychology's expansionism by disambiguating the expression 'laws of thought' (Frege 1998, 32:XV-XVII; see also Frege 1993, 30-1) and criticising those who conflate its distinct meanings.

'Psychologism' denotes the criticism initiated by Frege and championed by Husserl, and, historically, it marked a turning point in the relationship between logic and psychology. 'Psychologism' is not a precise notion; however, sociopsychological encroachments onto what is deemed logical, mathematical, epistemological or philosophical turf are accused of committing it (Kusch 2006; Kusch 2015b). Although psychologism in logic is not clearly defined, it represents a broad accusation that logical elements are being fallaciously conflated with mental phenomena (Sober 1978, sec. 1; George 1997; Jacquette 1997; Mohanty 1997; Jacquette 2003a, secs. 1, 2, 3; Kusch 2006; Pelletier et al. 2008, sec. 1.1; Urbanski 2011, sec. 2; Kusch 2015b; Kusch 2015a). In the earliest rebuttals of psychologism, anti-psychologists contended that logical justifications would no longer be possible if the distinction between laws of thought governing thinking and the laws of truth were lost (Hanna 2006, sec. 1.1; Haase 2009, sec. 2.2; Kusch 2015a, sec. 4; Lockhart 2016, 313-17).

It is testimony to the power of Frege's and Husserl's arguments that a strict division of labour between logicians, on the one hand, and psychologists and sociologists, on the other, represented the status quo for almost a century. More recently, however, interest in the psychologism/anti-psychologism debate is being rekindled (Jacquette 1997; Jacquette 2001; e.g., Jacquette 2003a; Hanna 2006), and naturalist tendencies in philosophy in general and cognitive science in particular are beginning to erode the strict division of labour in more recent decades (Jacquette 2003a, sec. 3; Kusch 2006, 2612; Kusch 2015b). In retrospect, some philosophers consider criticism of psychologism in logic to have been overzealous. In many respects, anti-psychologism in logic has become a dogma, and the faintest hint of using psychology as a potential source of evidence for logical theories, heretical, provoking damning accusations. A more differentiated critique of psychologism is advocated, discerning between justified criticism levelled at plump cases of untenable psychologism and unjustified criticism that has stifled research. (Jacquette 1997; Jacquette 2001; Jacquette 2003b)

Learning from actual practice through historical case studies in mathematics and the natural sciences has proven its worth in the philosophy of science, and this method is equally well justified in logic (Martin 2020). There are nevertheless limits to what can be learnt from practice. What is in contrast to what is considered to be acceptable as logical evidence may diverge radically, especially when external factors such as psychologism are in play. In this paper, I illustrate how psychology can be used as a source of evidence for logical theories by setting out how Jean Piaget used his psychological theory of reasoning as a source logical 
evidence. I also explore some consequences of tapping psychology as a source of logical evidence in the way Piaget suggested for the exceptionalism/anti-exceptionalism discourse on logic.

Jean Piaget (1950a, vol. 1, chap. Introduction) founded an interdisciplinary science of the growth of knowledge known as genetic epistemology (GE). Though narrower in scope, GE is a research program investigating the mind and its processes much like cognitive science, and logic is in its purview. Aiming to understand the nature of logic, Piaget investigated the laws of thought socio-psychologically. In contrast to some cognitive scientists though, he did not wish to erode Frege's disambiguation of laws of thought. According to Piaget, the demarcation is clear in theory; however, it was not always easy to maintain in practice due to inadequate methods in both logic and cognitive psychology. Thanks to progress in the formalisation and axiomatisation of logic, on the one hand, and the introduction of a psychogenetic approach to cognitive psychology, on the other, Piaget (Piaget and Grize 1972, vol. 15, sec. 2; see also Piaget 1957; Piaget and Beth 1966, vol. 12, chap. 7; Piaget 1977a; Piaget 2001, 30-35) believed, he respected Frege's disambiguation whilst showing how logic has its roots in psychological laws of thought.

In this paper, I begin with a psychological perspective on laws of thought, in which I expound Piaget's psychological theory of propositional reasoning. The exposition is quite detailed, and I apologise to readers, especially those familiar with Piaget's work, whilst begging their indulgence. The reason for the detail is that Piaget's theory of reasoning is still poorly understood (e.g., Bond 1978; Bond 2005; Johnson-Laird 2006, 249; Smith et al. 2009), but it is not only important for my argument to show that Piaget used psychology as evidence for a logical theory but that his use is plausible. Operations of thought are key to understanding Piaget's theory of reasoning, I therefore characterize them next before briefly outlining their development from elementary co-ordinations of actions to the equilibria they form at the operatory stages. Whilst having little direct bearing on logic, the diachronic perspective on operations of thought sheds light on the provenance of propositional reasoning and will prove helpful in assessing the impact of Piaget's theory on exceptionalism and anti-exceptionalism about logic. As well as a diachronic aspect, operations of thought also have a synchronic aspect. In equilibrium, the operations of thought form a structure, whose operatory mechanisms have regulatory effects on reasoning and therefore a have a direct bearing on a logic. 'Psycho-logic' is the term Piaget adopted to denote his psychological theory of reasoning, but he did not intend it to be a logical theory, despite the terminology; I therefore briefly characterize Piaget's understanding of psycho-logic before addressing the relationship he envisaged between logical theory and psycho-logic in the subsequent section.

Piaget did not formulate a logical theory; however, he characterised in general terms the sort of properties logical theories address by distinguishing between formal and real truth. I therefore briefly outline Piaget's demarcation of formal and real truth before moving on to consider those operations of thought that exhibit logical properties. Operations of thought in a state of equilibrium regulate the compositions of propositions in propositional reasoning; however, propositions do not necessarily follow from each other in any logical sense in these compositions. This section therefore begins by illustrating deductive operations with the help of one of the forms of implication Piaget decerned amid the compositions of operations of thought. I then proceed to set out how Piaget used such deductive operations to diagnose and resolve ex falso quodlibet, before reflecting more generally on his method. In the final section 
of this paper, I examine some repercussions of considering psychology as logical evidence in the way Piaget envisaged for exceptionalism and anti-exceptionalism about logic before concluding.

\section{Piaget's Theory of Propositional Reasoning}

Piaget describes how adolescents reason hypothetico-deductively when attempting to grasp connections between phenomena as follows:

Let us take as an example the implication $\mathrm{p} \supset \mathrm{q}$, and let us imagine an experimental situation in which a child between twelve and fifteen tries to understand the connections between phenomena which are not familiar to him but which he analyses by means of the new propositional operations rather than by trial and error. Let us suppose then that he observes a moving object that keeps starting and stopping and he notices that the stops seem to be accompanied by lighting of an electric bulb. The first hypothesis he will make is that the light is the cause (or an indication of the cause) of the stops, or $\mathrm{p} \supset \mathrm{q}$ (light implies stop). There is only one way to confirm the hypothesis, and that is to find out whether the bulb ever lights up without the object stopping, or $p \bar{q}(p \bar{q}$ is the inverse of or negation of $p \supset q)$. But he may also wonder whether the light, instead of causing the stop, is caused by it, or $q \supset p$ (now the reciprocal and not the inverse of $\mathrm{p} \supset \mathrm{q}$ ). To confirm $\mathrm{q} \supset \mathrm{p}$ (stop implies light), he looks for the opposite case which would disconfirm it; that is, does the object ever stop without the light going on? This case, $\bar{p} q$, is the inverse of $\mathrm{q} \supset \mathrm{p}$. The object stopping every time the light goes on is quite compatible with its sometimes stopping for some other reason. Similarly, $\mathrm{p} \overline{\mathrm{q}}$, which is the inverse of $\mathrm{p} \supset \mathrm{q}$, is also the correlative of $\mathrm{q} \supset \mathrm{p}$. If every time there

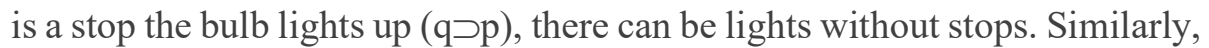
if $q \supset p$ is the reciprocal of $\mathrm{p} \supset \mathrm{q}$, then $\overline{\mathrm{p}} \mathrm{q}$ is also the reciprocal of $\mathrm{p} \overline{\mathrm{q}}$. (Inhelder and Piaget 1969, 139)

\begin{tabular}{|c|c|c|c|c|c|c|c|c|c|c|c|c|c|c|c|}
\hline 1 & 2 & 3 & 4 & 5 & 6 & 7 & 8 & 9 & 10 & 11 & 12 & 13 & 14 & 15 & 16 \\
\hline$p \cdot q$ & - & $p \cdot q$ & - & - & $p \cdot q$ & $p \cdot q$ & - & $p \cdot q$ & - & $p \cdot q$ & - & $p \cdot q$ & - & $p \cdot q$ & - \\
\hline $\mathrm{p} \cdot \overline{\mathrm{q}}$ & - & $\mathrm{p} \cdot \overline{\mathrm{q}}$ & - & $\mathrm{p} \cdot \overline{\mathrm{q}}$ & - & - & $\mathrm{p} \cdot \overline{\mathrm{q}}$ & $\mathrm{p} \cdot \overline{\mathrm{q}}$ & - & - & $\mathrm{p} \cdot \overline{\mathrm{q}}$ & $\mathrm{p} \cdot \overline{\mathrm{q}}$ & - & - & $\mathrm{p} \cdot \overline{\mathrm{q}}$ \\
\hline$\overline{\mathrm{p}} \cdot \mathrm{q}$ & - & $\overline{\mathrm{p}} \cdot \mathrm{q}$ & - & $\overline{\mathrm{p}} \cdot \mathrm{q}$ & - & $\overline{\mathrm{p}} \cdot \mathrm{q}$ & - & - & $\overline{\mathrm{p}} \cdot \mathrm{q}$ & - & $\overline{\mathrm{p}} \cdot \mathrm{q}$ & - & $\overline{\mathrm{p}} \cdot \mathrm{q}$ & $\overline{\mathrm{p}} \cdot \mathrm{q}$ & - \\
\hline$\overline{\mathrm{p}} \cdot \overline{\mathrm{q}}$ & - & - & $\overline{\mathrm{p}} \cdot \overline{\mathrm{q}}$ & $\overline{\mathrm{p}} \cdot \overline{\mathrm{q}}$ & - & $\overline{\mathrm{p}} \cdot \overline{\mathrm{q}}$ & - & $\overline{\mathrm{p}} \cdot \overline{\mathrm{q}}$ & - & $\overline{\mathrm{p}} \cdot \overline{\mathrm{q}}$ & - & - & $\overline{\mathrm{p}} \cdot \overline{\mathrm{q}}$ & - & $\overline{\mathrm{p}} \cdot \overline{\mathrm{q}}$ \\
\hline $\begin{array}{l}\sigma \\
* \\
2\end{array}$ & 0 & $\stackrel{\sigma}{2}$ & $\begin{array}{l}10 \\
12\end{array}$ & $\frac{\sigma}{2}$ & $\begin{array}{l}\sigma \\
\dot{2}\end{array}$ & $\begin{array}{l}\sigma \\
\bigcap_{2}\end{array}$ & 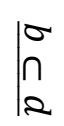 & $\begin{array}{c}2 \\
\bigcap \\
\sigma\end{array}$ & $\left.\right|_{n} ^{2}$ & $\begin{array}{c}\sigma \\
\text { III } \\
2\end{array}$ & $\begin{array}{l}\sigma \\
3 \\
2\end{array}$ & $\frac{\sigma}{2}$ & $\frac{\sigma}{2}$ & $\frac{2}{\sigma}$ & $\frac{\sqrt{2}}{\sigma}$ \\
\hline
\end{tabular}

Table 116 Logical Operators of Interpropositional Operations. The true conjunctions comprise the columns of this table, and the columns are set out in pairs comprising the full complement of four conjunctions. Connecting the conjunctions in each column disjunctively gives rise to the disjunctive normal form of the logical operators in the bottom row. Except for *, $w$, $\mathrm{p}[\mathrm{q}]$, and $\mathrm{q}[\mathrm{p}]$ the binary operators are familiar. * represents the complete affirmation; $w$, exclusive disjunction, and $\mathrm{p}[\mathrm{q}]$ as 
well as $\mathrm{q}[\mathrm{p}]$ are affirmations of $\mathrm{p}$ and q conjointly with either $\overline{\mathrm{q}}$ or $\overline{\mathrm{p}}$ respectively. ${ }^{2}$ (Based on Table 100 Piaget and Grize $1972,214)$

More generally, given any two observable phenomena represented by propositions $\mathrm{p}$ and $\mathrm{q}$, it is not immediately obvious how they are in fact related to each other. Nevertheless, four combinations of these phenomena, represented by the conjunctions $p \cdot q, \bar{p} \cdot q, p \cdot \bar{q}$ and $\bar{p} \cdot \bar{q}$, are potentially observable. Individually, each observation does not allow the relationship between the phenomena to be determined; observation of $p$ and $q$ always occurring together $(p \cdot q)$, for example, means that $p$ and $q$ could be related in any of 8 ways ( $p \cdot q$ occurs in 8 columns of Table 1). Through observation of all four possible coincidences of the phenomena, however, the relationship can be uniquely determined. Observation of $p \cdot q$ and $\bar{p} \cdot \bar{q}$ occurring without exception but no cases of either $\bar{p} \cdot q$ or $p \cdot \bar{q}$, for example, shows that the phenomena represented by $p$ and $q$ are equivalent; whereas observation of $p \cdot q, \bar{p} \cdot q$, and $p \cdot \bar{q}$ but no cases of $\bar{p} \cdot \bar{q}$ means that $p \vee q$ (see Table 1). Conversely, if $p \supset q$ is postulated, $p \cdot q, \bar{p} \cdot q$, and $\bar{p} \cdot \bar{q}$ are observations that are commensurate with the hypothesis, but $p \cdot \bar{q}$ would falsify it. In short, a framework of theoretically possible relations between phenomena based on combinations of observations thus mediates the discovery of the factual relationship between phenomena. (Smith 1987, sec. Piaget's Logic: A Constructivist Interpretation)

In part, GE explains the ability to reason hypothetico-deductively by describing how it develops from more elementary forms of reasoning, and operations of thought are key to the diachronic explanation.

\subsection{Operations of thought}

Piaget understands propositions as meaningful categorical statements that are true or false, and writes $\mathrm{p}, \mathrm{q}, \mathrm{r}, \ldots$ and $\overline{\mathrm{p}}, \overline{\mathrm{q}}, \overline{\mathrm{r}}, \ldots$ for the affirmations and their negations. With respect to propositions, he defines two types of operation. One type consists in combining propositions with others to form new propositions with well-defined truth conditions; for example, the conditional $p \supset q$ (if $p$ then $q$ ) will be a new false proposition in the one case when $p$ is true and $q$ false; the conjunction $p \cdot q(p$ and $q$ ) will be a new true proposition only if $p$ and $q$ are both true, etc. Since these operations combine propositions as wholes using propositional connectives, he denotes them 'interpropositional operations' (Piaget and Grize 1972, 15:34).

Another type of operation decomposes propositions into their constituent parts and transforms them into new propositions by modifying these parts; for example, in a proposition such as 'this rose is red', the subject 'this rose' can by replaced by other terms ('flag', 'all the roses', etc.), the predicate 'red' by others ('yellow', 'black', etc.), or the connection between subject and predicate 'is' can be modified ('this rose excels this one in beauty', etc.). Since these operations are performed on the innards of propositions, Piaget denotes them 'intrapropositional operations' (Piaget and Grize 1972, 15:35).

\footnotetext{
${ }^{2}$ Piaget pursued constructivist ends when modelling propositional reasoning and found it convenient to use the symbolism of propositional logic; however, he stresses that the symbols do not have the familiar logical meanings (Piaget and Beth 1966, 12:180-1; Apostel 1982). The formalism was only partially revised in the second edition to bring it more in line with logical conventions (Piaget and Grize 1972, 15:XVI; cf. Seltman and Seltman 1985). To facilitate referencing, I adopt Piaget's notation for the logical operators although it is partially antiquated and idiosyncratic.
} 
Piaget's terminology is adopted in this paper; however, merely denoting their effects on propositions and their parts does not make any commitment to the psychological nature of operations. Psychologically, Piaget characterises operations as follows:

operations are actions which are internalizable, reversible, and coordinated into systems characterized by laws which apply to the system as a whole. They are actions, since they are carried out on objects before being performed on symbols. They are internalizable, since they can also be carried out in thought without losing their original character of actions. They are reversible as against simple actions which are irreversible. In this way, the operation of combining can be inverted immediately into the operation of dissociating, whereas the act of writing from left to right cannot be inverted to one of writing from right to left without a new habit being acquired differing from the first. Finally, since operations do not exist in isolation they are connected in the form of structured wholes (Piaget 1957, 8; Piaget and Beth 1966, 12:172; Piaget 1971a, 21-2; see also Piaget and Grize 1972, 15:55; Piaget 2001, chap. 2)

\subsection{Psychogenesis of Operations of Thought}

Operations of thought can be better grasped through their development. According to Piaget (e.g., Piaget 1952; Piaget 1971b; Piaget 1977b; Piaget 1977c; Piaget 2001), intelligence has its roots in the biological organism and develops in a sequence of stages over time. Although the number of stages in Piaget's works varies, the sensorimotor, semiotic, concrete- and formal-operational stages are widely accepted (Kesselring 2009). These stages can be more broadly categorised into the pre-operational - the sensorimotor, semiotic - and operationalconcrete- and formal-operational - stages. Intra- and interpropositional operations occur in the operational stages.

Living organisms are open, self-regulating systems, according to Piaget. As such, they dependent existentially on their environments, and through self-regulation they strive to maintain equilibrium between biological integrity and environmental demands. Cognition is the natural continuation of biological adaptation, and cognition, just like the biological organism, strives to remain in equilibrium with its environment.

Cognitive equilibria are achieved at the operational stages, but they are presaged by the coordinations of voluntary actions involving sensory stimuli and motor responses during the sensorimotor stage. The advent of language at the semiotic stage then heralds a change. The enactive world constructed at the sensorimotor stage gradually becomes immersed in a world of representations, and the effects of this immersion are twofold: on the one hand, the representational world not only encompasses the enactive reality constructed at the sensorimotor stage but transcends it in all directions; on the other hand, the manipulations of objects can now be performed solely in the mind without the aid of physical manipulation.

The latter development is interiorization, and a whole new level of interiorization is achieved with the advent of operations.

Operations are interiorised actions, and just as actions occur in coordination with other actions, operations occur in concert with others; equilibrium is achieved, however, when operations are coordinated with others to form closed systems of transformations that are completely reversible. With the emergence of the equilibria, description of the provenance of 
operations and therefore the diachronic aspect of a psychological explanation of reasoning is complemented by a synchronic aspect. In equilibrium, the operations form structured wholes amenable to formalisation using the algebraic tools of logic.

Before moving on to the details of the structured wholes formed by operations in equilibrium, a few words need to be said on the genetic-epistemological approach to explanation. According to Piaget, two different perspectives must be borne in mind in any psychological explanation. In common with any other science, psychological explanation has a third-person perspective, namely the psychologists' as observers, and it is adopted in the diachronic and synchronic descriptions of operations. In contrast to natural sciences, however, there is also a first-person perspective, namely, the subjective experience of individuals who are in the process of cognitive development. The subjective experience is what an individual takes to be true at any stage of cognitive development regardless of whether it is actually true. The subjective experience changes over time, and psychologists aim to explain these changes by 'proceeding from the outside to the inside and not the other way around, namely, seeing in conscious implications the product of becoming aware of the organization of actions' (Piaget and Grize 1972, 15:14 my translation).

Clearly, as subjective experience converges with accepted norms of truth in the course of cognitive development, logical truths and their purportedly special properties would be within the purview of psychological explanation.

\subsection{The Interpropositional Grouping of Operations}

Reasoning used as a cognitive tool helps determine the relationship between phenomena by hypothetico-deductive means. Hypotheses are formed on the basis of evidence, and as new evidence becomes available, they are confirmed or falsified; in the latter case, new hypotheses are formed to replace the old. In other words, reasoning is a dynamic process; Table 1, on the other hand, does not capture this dynamism; it simply presents correspondences of relationships between phenomena and observations. Operations of thought introduce the dynamism into the static correspondences, and, in equilibrium, they form closed systems of transformations.

Given two propositions $p$ and q representing two phenomena, the four conjunctions $p \cdot q, p \cdot \bar{q}$, $\overline{\mathrm{p}} \cdot \mathrm{q}$, and $\overline{\mathrm{p}} \cdot \overline{\mathrm{q}}$ represent possible observable combinations of phenomena, and the 16 distinct relations between the phenomena are set out in Table 1. On the one hand, the columns of Table 1 are organised into complementary pairs with respect to the full complement of conjunctions, and the outcome of composing them disjunctively or conjunctively is the complete affirmation or complete negation, respectively. In the words, the complementary pairs are exhaustive and complementary, and such compositions correspond to laws of thought, namely excluded middle and non-contradiction. On the other hand, the logical operators can be transformed into each other; beginning with the equivalence

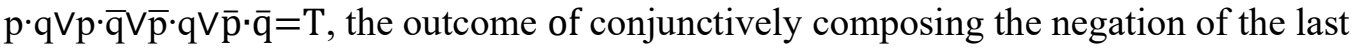
conjunction with both sides of the equivalence, for example, is $[p \cdot q \vee p \cdot \bar{q} \vee \bar{p} \cdot q \vee \bar{p} \cdot \bar{q}] \cdot$ $\overline{(\bar{p} \cdot \bar{q})}=T \cdot \overline{(\bar{p} \cdot \bar{q})}$, i.e., $p \cdot q \vee p \cdot \bar{q} \vee \bar{p} \cdot q=\overline{(\bar{p} \cdot \bar{q})}$ or $p \vee q$ since $(p \vee q)=\overline{(\bar{p} \cdot \bar{q})}$. Algebraically, the transformation amounts to negating conjunctions of the complete affirmation and moving them to the opposite side of the equivalence, where they are composed conjunctively with the complete affirmation; in actual reasoning, however, it corresponds to excluding the possibility of observing the particular combination of 
phenomena represented by $\bar{p} \cdot \bar{q}$. Moreover, $(p \mid q) \cdot \overline{(\bar{p} \cdot \bar{q})}=(p w q)$, for example, and $(\mathrm{p} w \mathrm{q}) \mathrm{V}(\overline{\mathrm{p}} \cdot \overline{\mathrm{q}})=(\mathrm{p} \mid \mathrm{q})$. Incompatibility is then a reciprocal exclusion composed disjunctively with a joint negation. Conversely, the common part of an incompatibility (p|q) and a disjunction $\overline{(\bar{p} \cdot \bar{q})}=(p \vee q)$ is $[(p \cdot \bar{q}) \vee(\bar{p} \cdot q)]$, which is a reciprocal exclusion (pwq). In other words, the logical operators can be transformed into each other. In fact, the logical operators are the operands of a system of transformations ${ }^{3}$, and the laws governing the transformations are those of a grouping:

1. The direct operation is the disjunctive union $\vee$ of conjunctions; e.g., (o) $\vee(p \cdot q)$; (p·q) $\vee(p \cdot \bar{q})$; etc.

2. The inverse operation is the negation of a conjunction united conjunctively; e.g., $\cdot \overline{(p \cdot q)} ; \cdot \overline{(p \cdot \bar{q})}$; etc.

3. The general identity operation Vo leaves the elements it is composed with unaltered, e.g., $(p \cdot q) \vee(o)=(p \cdot q)$; and it is the product of the direct and inverse operations, e.g., $(\mathrm{p} \cdot \mathrm{q}) \cdot \overline{(\mathrm{p} \cdot \mathrm{q})}=\mathrm{o}$.

4. The special identities are:

a) Tautology: $(p \cdot q) \vee(p \cdot q)=(p \cdot q)$

b) Reabsorption: $(p \cdot q) \vee[(p \cdot q) \vee(p \cdot \bar{q})]=[(p \cdot q) \vee(p \cdot \bar{q})]$

c) Absorption: $(p \cdot q) \cdot\left(p^{*} q\right)=(p \cdot q)$

5. Associativity is limited due to the intervention of special identities; e.g., $p \cdot q \vee(\bar{p} \cdot \bar{q} \vee \bar{p} \cdot q)=p \supset q=(p \cdot q \vee \bar{p} \cdot \bar{q}) \vee \bar{p} \cdot q ;$ however, $p \cdot q \vee((p \cdot q) \cdot \overline{(p \cdot q)}) \neq(p \cdot q \vee p \cdot q) \cdot \overline{(p \cdot q)}$ because $p \cdot q \vee((p \cdot q) \cdot \overline{(p \cdot q)})=p \cdot q \vee o=p \cdot q$ but $(p \cdot q \vee p \cdot q) \cdot \overline{(p \cdot q)}=p \cdot q \cdot \overline{(p \cdot q)}=o$.

In summary, the operations of the grouping engender the 16 distinct logical operators and form a closed system of transformations on them. This grouping is thus a structured whole operations of thought achieve in a state of equilibrium, and it serves as a cognitive tool for rationally determining relations between phenomena.

\subsection{Psycho-Logic}

Piaget adopted the terminology 'psycho-logic' or 'logico-psychology' for the formalisation of the essential operatory mechanisms of reasoning. Despite the terminology, however, psychologic is not a logic. It is not concerned with the validity of inferences, and it does not provide techniques for assessing them; it does, however, utilise logic. Piaget understands psychologic in analogy to mathematical physics. Physics investigates the physical world experimentally, and correspondence with empirical evidence is its truth criterium; mathematics, on the other hand, is neither based on experiment nor does its truth depend on correspondence with empirical evidence. It is a formal science whose truth depends solely on the consistency of the deductive systems constructed. With the aim of explaining the physical world, mathematical physics draws on both deductive and empirical sources and applies mathematics to physics to construct a formal theory based on the experimental findings of physics. Like mathematical physics, Piaget (1957, 25; see also Bond 1978; Bond 2005) also envisages psycho-logic or logico-psychology as a tertium quid. On the one hand, psychology investigates mental life empirically, and its criterion for truth is correspondence with psychological facts; on the other hand, logic is concerned with validity and has developed

\footnotetext{
${ }^{3}$ Since the logical operators are simply alternative expressions for disjunctions of conjunctions, the 16 logical operators are the operands of the grouping (cf. Seltman and Seltman 1985).
} 
algebraic tools. Psycho-logic is an application of these tools to the findings of experimental psychology; specifically, it models operations of thought using the algebraic tools logic puts at its disposal.

\section{Logic as a Mirror of Thought}

While criticising Denkpsychologie, Piaget $(2001,27)$ concluded that logic is the mirror of thought rather than thought being the mirror of logic as the Denkpsychologen claimed. Having thought mirror the laws of identity, non-contradiction and excluded middle would invest logical laws with causal agency, thus committing reverse psychologism; having logic mirror thought, on the other hand, does not. A mirror reflects the parabolic trajectory of a projectile under the influence of Earth's gravity, for example; however, it the projectile itself not its reflection looming large in the mirror on impact that shatters the mirror.

Only the visual aspects of a projectile's motion are reflected in a mirror. By invoking the mirror metaphor for logic, Piaget therefore provoked questions concerning the corresponding phenomenon. According to Piaget (Piaget and Grize 1972, 15:4-7), logic like epistemology occupies itself with statements that are capable of being true or false; however, he delineated them by contrasting formal and real truth. Real truth refers to the correspondences between propositions and facts discovered in the empirical sciences, and it is the concern of epistemology; formal truth, on the other hand, refers to the agreement and disagreement of propositions that are simply taken to be true or false rather than the correspondence of propositions and fact. Since the interpropositional grouping models states of equilibrium achieved by operations of thought, psycho-logic is concerned with real truth. Formal truth on the other hand is concerned with coherence, contradiction, the internal validity of systems of propositions, i.e., how they imply, are necessary consequences, entail, or exclude each other, etc. In terms of Piaget's distinction between real and formal truth, the latter corresponds to the visual aspect of the projectile's motion reflected in the mirror, and the examples listed are typical of the logical properties logical theories address (e.g., Priest 2016, 39; Hjortland 2017, 641; Hjortland 2019, sec. 2). However, Piaget never, to my knowledge, formulated a logical theory; nevertheless, with formal truth, he has delineated the sort of properties of propositions he would target, and they correspond to the logical properties logical theories typically address.

While well-chosen metaphors can be helpful heuristics in the search for explanations, they are not substitutes for positive explanations, and, as helpful as the mirror metaphor is, it obscures as well as clarifies the relationship between thought and logic. Being primarily an epistemologist not a logician, formal truth did not mark the boundary of Piaget's interests; he also wanted to know 'what it [formal truth] is the form of' (Piaget and Grize 1972, 15:7). In other words, just as reflections in a mirror are images of something real, formal truth is according to Piaget the form of a positive reality. Hence, Piaget was not ultimately content with a metaphor, and, after several approximative iterations, he finally concluded that logic is 'the formal theory of deductive operations' (Piaget and Grize 1972, 15:20 authors' italics).

Piaget's formulation raises a host of questions; however, I will restrict myself to the following two groups of questions and address them separately in the two subsequent sections: First, how do deductive operations differ from operations of thought? and, what logical properties do they present for Piaget's formal theory to target? Second, how does 
psychology inform a logical theory, according to Piaget? And how does Piaget envisage a formal theory mirroring deductive operations?

\subsection{Deductive Operations}

According to Piaget, the affirmation and negation of a single proposition $\mathrm{p}$ already forms an interpropositional grouping, and, in his rational reconstruction of the genesis of the interpropositional grouping involving multiple propositions, the conditional operator plays a pivotal role (Piaget and Grize 1972, vol. 15, sec. 39). Composing $\mathrm{p}$ and $\overline{\mathrm{p}}$ disjunctively gives rise to the complete affirmation $\mathrm{p} \vee \overline{\mathrm{p}}=\mathrm{T}$; conjunctively, complete negation $\mathrm{p} \cdot \overline{\mathrm{p}}=\mathrm{O}$. Along with $\mathrm{p}$ and $\overline{\mathrm{p}}, \mathrm{o}$ and $\mathrm{T}$ are therefore also operands of this elementary grouping, and the conditional unlike many other logical operators is already defined $\mathrm{p} \supset \mathrm{T}=\mathrm{p} \cdot \mathrm{TV} \overline{\mathrm{p}} \cdot \mathrm{TV} \overline{\mathrm{p}} \cdot \overline{\mathrm{T}}$. Since $\overline{\mathrm{T}}=\mathrm{o}$, the conditional operator reduces to the affirmation $T[p]=p \cdot T \vee \bar{p} \cdot T ; p$ therefore has common and non-common parts with $\mathrm{T}$, namely $\mathrm{p} \cdot \mathrm{T}$ and $\overline{\mathrm{p}} \cdot \mathrm{T}$, and the direct operation of the grouping unites them into a whole $\mathrm{p} \cdot \mathrm{TV} \overline{\mathrm{p}} \cdot \mathrm{T}=\mathrm{T}$.

The part-whole relationship between propositions is characteristic of implication, and Piaget propagated it by introducing a proposition $q$ between $p$ and $T$ such that $q=p q \vee \bar{p} q$, where $q$ now plays an analogous role for $\mathrm{p}$ as $\mathrm{T}$ once did for $\mathrm{p}$ in the elementary grouping. The noncommon part, $\overline{\mathrm{p}} \mathrm{q}$, is then the relative complement of $\mathrm{p}$ in $\mathrm{q}$, and Piaget denotes it $\mathrm{p}$; $\mathrm{q}$ can therefore be expressed more concisely as $q=p \vee p$ '. Proceeding analogously for further propositions, $r=q \vee q$ ', where q' $=r \cdot \bar{q}$; s=rVr', where r' $=s \cdot \bar{r}$; etc. (see Fig. 1).

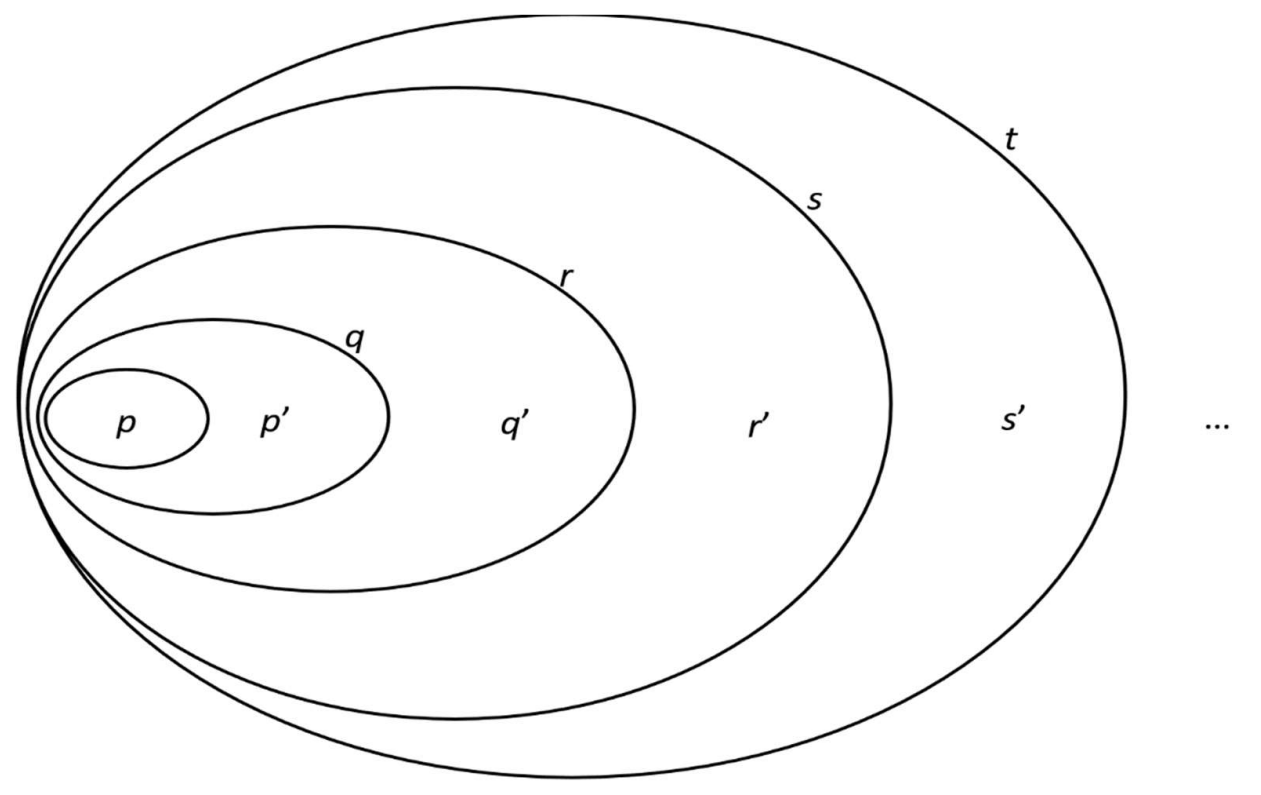

Fig. 1 Grouping of Implications - Form I. Piaget calls p, q, r, s, t ... primary propositions and their relative complements $\mathrm{p}^{\prime}=\mathrm{q} \cdot \overline{\mathrm{p}}, \mathrm{q}^{\prime}=\mathrm{r} \cdot \overline{\mathrm{q}}, \mathrm{r}^{\prime}=\mathrm{s} \cdot \overline{\mathrm{r}}$... secondary propositions. Primary propositions in the hierarchy are composed of the primary and secondary propositions of the previous level as follows: q=pVp'; r=qVq'; s=rVr'; ... Form I corresponds to the hierarchical nesting of classes in a classification (Piaget and Grize 1972, p. 324 Fig. 46)

This construction is one of four forms of implication. Piaget denoted it Form I (Piaget and Grize 1972, 15:324-7), and it is analogous to the inclusion of classes $\mathrm{P} \subset \mathrm{Q} \subset \mathrm{R} \subset \mathrm{S} \subset$ etc. 
familiar from biological taxonomies, genealogies, etc. Piaget (Piaget and Grize 1972, 15:103) denoted these classes 'primary', and each primary class has a relative complement P', Q', R' etc., which he (Piaget and Grize 1972, 15:103) denoted 'secondary' classes. The grandchildren of a grandparent $\mathrm{R}$, for example, are comprised of the children of one of R's children $\mathrm{P}$ and their first cousins $\mathrm{P}$ '. In terms of primary and secondary classes, the classes constituting the nesting inclusions are therefore as follows:

$\mathrm{PUP}^{\prime}=\mathrm{Q}, \mathrm{QUQ} \mathrm{Q}^{\prime}=\mathrm{R}, \mathrm{RUR}{ }^{\prime}=\mathrm{S}$, etc.

Let propositions $\mathrm{p}, \mathrm{q}, \mathrm{r}$, s, etc. express the membership of an element in the primary classes $\mathrm{P}$, Q, R, S, etc., and p', q', r', etc., membership of an element in the secondary classes P', Q', $\mathrm{R}$ ', etc. Clearly, if $q$ is true, the element $\mathrm{x}$ is a member of $\mathrm{Q}=\mathrm{PUP}$ '; $\mathrm{x}$ is therefore a member of either P or P', i.e., pVp'; Form I therefore corresponds to the nesting inclusions of classes typically found in Pyphorian trees. In fact, the intrapropositional operations on such classes also constitute groupings, and Form I models one of these groupings in terms of propositions (Piaget and Grize 1972, 15:324). For the present purposes, however, the correspondence with nesting inclusions of classes simply facilitates recognition of implications. Clearly, if $\mathrm{x}$ is an element of a class in this construction, it is automatically a member of all the class's superclasses; correspondingly, primary p, q, r, etc. and secondary p', q', r', etc. propositions therefore imply primary propositions of higher rank; for example, $\mathrm{p}^{\prime}$ implies $\mathrm{t}$ or $\mathrm{r}$ implies $\mathrm{u}$, etc. Conversely, if $\mathrm{x}$ is a member of a primary class, it must be a member of one of the disjoint classes composing it; each primary proposition therefore implies those propositions composing it but as a whole; for example, s implies ( $\left.p \vee p^{\prime} \vee r^{\prime}\right)$. Finally, any subclass of a primary class of higher order can be determined by eliminating relative complementaries; any proposition can therefore be inferred from those of higher rank by negating complementaries; e.g., $\mathrm{q}^{\prime}=\mathrm{t} \cdot \overrightarrow{\mathrm{s}} \cdot \overrightarrow{\mathrm{r}} \cdot \overline{\mathrm{q}}$. In short, Form I is a construction in the interpropositional grouping that engenders a 'play of implications' (Piaget and Grize 1972, 15:343).

From a logical viewpoint, an explication of the nature of the implications at play is required. Before embarking on such an explication, though, the transition from operations of thought to a play of implications via deductive operations gives pause for thought. Operations are integral to the psychological explanation of reasoning. They have a regulatory function on reasoning; however, reasoners are not necessarily aware of them when reasoning. Operations therefore belong almost exclusively to the third-person perspective, namely, the psychological model of reasoning. For reasoners, on the other hand, certain propositions appear to follow from others; implications therefore have a first-person aspect as well. Moreover, structures within the interpropositional grouping, the forms of implications namely, mediate between these perspectives. The transition from operations to implications via the forms of implication thus illustrate how psychological explanation moves from the outside to the inside.

Returning to the nature of the implications after the brief excursion into psychological explanation, Piaget based the interpropositional grouping on Boolean structures (Grize 2013, 152), and a Boolean algebra is a complemented distributive lattice (Rutherford 1966; Halmos and Givant 1998). Lattice theory is therefore a possible perspective on the interpropositional grouping; and, with the help of Rutherford's Introduction to Lattice Theory (Rutherford 1966, secs. $1-4,12 \& 17$ esp.), I will attempt to shed some light on the nature of the implications engendered by deductive operations of thought. 
A lattice can be defined in two ways. On the one hand, it is a partially ordered set in which any two elements have both a least upper bound (meet) and a greatest lower bound (join). For elements $\mathrm{x}$ and $\mathrm{y}$ of a lattice $\mathcal{L}$, the meet is denoted $\mathrm{x} \cup \mathrm{y}$ and the join $\mathrm{x} \cap \mathrm{y}$. A partially ordered set is an algebraic system in which a binary relation $\mathrm{x} \geqq \mathrm{y}$, known as an inclusion or order relation, is defined. On the other hand, a lattice is also a set $\mathcal{L}$ of elements with two binary operations $\cap$ and $U$, which satisfy commutative, associative, and absorptive laws. Moreover, the two definitions can be shown to be equivalent via the identity $y=x \cap y \equiv x \geqq y \equiv x \cup y=x$.

Logical operators have many different guises. Nevertheless, disparate guises can be shown to be equivalent by reducing them to their normal forms. Table 1 therefore represents a classification of equivalent logical operators via their normal forms. $\{p q \vee \bar{p} q \vee p \bar{q} \vee \bar{p} \bar{q}\}(\{T\}$ for short), for example, represents the class of tautologies $\mathrm{p} \vee \overline{\mathrm{p}}, \mathrm{q} \overline{\mathrm{q}}$, etc.; $\{\mathrm{o}\}$, contradictions $\mathrm{p} \wedge \overline{\mathrm{p}}, \mathrm{q} \wedge \overline{\mathrm{q}}$, etc.; $\{\mathrm{pq} \vee \overline{\mathrm{p}} \mathrm{q} \vee \mathrm{p} \overline{\mathrm{q}}\}$, disjunction in its various guises $\mathrm{p} \vee \mathrm{q}, \overline{(\bar{p} \bar{q})}, \mathrm{p} \vee q \vee q$, etc. Since the propositional connectives $\vee, \wedge$, and ${ }^{-}$are congruent to operations $\cup, \cap$, and ', respectively, on these classes, the operations of the grouping correspond to operations on the equivalence classes of the classification of logical operators. $(p w q) \vee p q=(\bar{p} q \vee p \bar{q}) \vee p q=p \vee q$, for example, transforms $\mathrm{p} w \mathrm{q}$ into $\mathrm{p} \vee \mathrm{q}$ via the direct operation $\vee \mathrm{pq}$, and it corresponds to $\{\bar{p} q \vee p \bar{q}\} \cup\{p q\}=\{\bar{p} q \vee p \bar{q} \vee p q\}$ in terms of classes; transforming $p \vee q$ back to $p w q$ via the inverse operation $\wedge \overline{(\mathrm{pq})}$, on the other hand, corresponds to the relative complement of $\{\mathrm{pq}\}$ in $\{\mathrm{p} \vee \mathrm{q}\}=\{\mathrm{pq} \vee \mathrm{p} \overline{\mathrm{q}} \vee \overline{\mathrm{p}} \mathrm{q}\}$, i.e., $\{\overline{\mathrm{p}} \mathrm{q} \vee \mathrm{p} \overline{\mathrm{q}}\}=\{\mathrm{p} w \mathrm{q}\}$.

In $\mathrm{CL}, \mathrm{p} \supset \mathrm{q}$ has the same truth conditions as $\overline{\mathrm{p}} \vee \mathrm{q}$, namely, true except when $\mathrm{p}$ is true and $\mathrm{q}$ is false. Since arbitrary propositions may be substituted into the variables $p$ and $q$, it is clearly not possible to preclude the falsity of $\mathrm{p} \supset \mathrm{q}$ without imposing further constraints. $\mathrm{p} \supset \mathrm{q}$ is a member of the same class as $\bar{p} \vee q$, namely, $\{p q \vee \bar{p} q \vee \overline{p q}\}$, and, in a free Boolean algebra, the postulates of a complemented distributive lattice constitute the only constraints. To determine the additional constraints required to make $\bar{p} \vee q$ true without exception, consider classes of propositions $\{\mathrm{p}\},\{\mathrm{q}\}$ and $\{\mathrm{p}\} \mathcal{\prime}^{\prime}\{\mathrm{q}\} \cdot \overline{\mathrm{p}} \vee \mathrm{q}$ is true without exception on condition $\{p\}{ }^{\prime} \cup\{q\} \in\{T\}$; i.e., $\{q\}$ is in the interval $[\{p\},\{T\}]$ or $\{q\} \geqq\{p\}$.

Although simply an alternative representation of the equivalence classes in Table 1, a Hasse diagram (see Fig. 2) aids visualisation of the inclusions ordering the classes of propositions. Referring to Fig. 2, the condition $\{p\}{ }^{\prime} \cup\{q\} \in\{T\}$ is fulfilled provided $\{q\}$ occupies a node on a line connecting $\{\mathrm{p}\}$ with $\{\mathrm{T}\}$; for example, $\mathrm{p}[\mathrm{q}], \mathrm{q}[\mathrm{p}], \mathrm{p} \vee \mathrm{q}$, etc., are propositions belonging to classes on lines connecting $\{\mathrm{pq}\}$ with $\{\mathrm{T}\}$; and since the unions of their corresponding classes with $\{\mathrm{pq}\}$ ' are members of $\{\mathrm{T}\}$, the implications pq $\supset \mathrm{p}[\mathrm{q}], \mathrm{pq} \supset \mathrm{q}[\mathrm{p}], \mathrm{pq} \supset \mathrm{p \vee q}$, etc. are true without exception. In terms of Table 1, pq thus implies in this way all those logical operators in whose disjunctive normal form it occurs. 


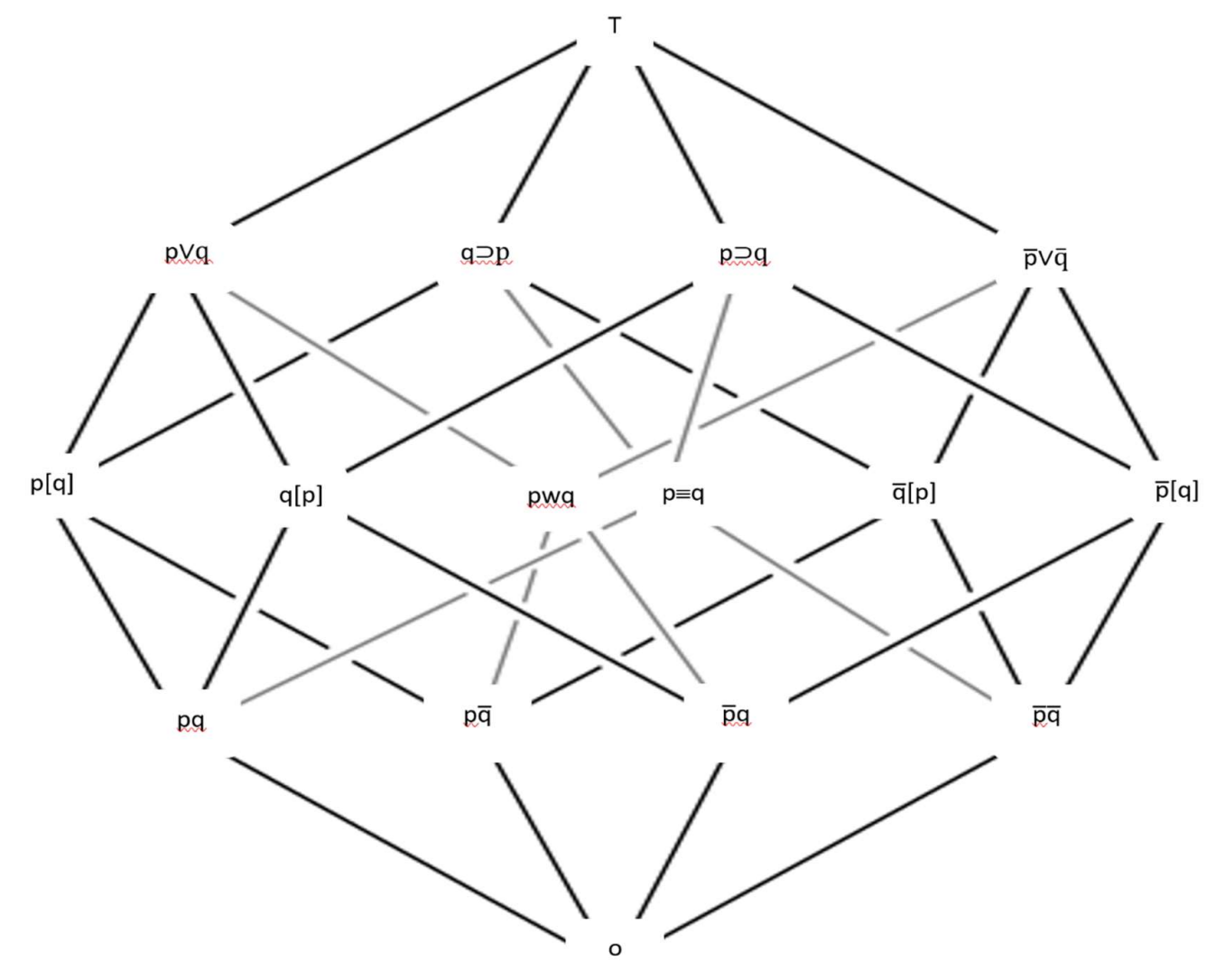

Fig. 2 Hasse Diagram of the 16 Logical Operators of Propositional Logic. The figure represents the projection on to the plane of a four-dimensional cube. The logical operators occupy points of intersecting lines, and the lines connecting points represent inclusion relations. Thus $\mathrm{p} \supset \mathrm{q} \geqq \mathrm{p} \equiv \mathrm{q}, \mathrm{q}[\mathrm{p}], \overline{\mathrm{p}}[\mathrm{q}], \mathrm{pq}, \overline{\mathrm{p} q}, \overline{\mathrm{pq}}$ and $\mathrm{o}$; but not $\mathrm{p} \overline{\mathrm{q}}$. (After Rutherford 1966, Fig. 7)

Rutherford distinguished different 'categories of propositions' $(1966,50)$ and ordered them hierarchically into elementary propositions, propositions about elementary propositions and propositions about propositions about elementary propositions. $\mathrm{p} \equiv \mathrm{q}$, for example, is a proposition about the elementary propositions $\mathrm{p}$ and $\mathrm{q}$, namely, that they are true together or false together; and $\mathrm{p} \equiv \mathrm{q}$ can also be formally true, i.e., true for all substitutions of $\mathrm{p}$ and $\mathrm{q}$. Correspondingly, $\mathrm{p} \supset \mathrm{q}$ is a proposition about elementary propositions $\mathrm{p}$ and $\mathrm{q}$, and, $\mathrm{p} \supset \mathrm{q}$ can also be formally true, i.e., true for any substitutions of $p$ and $q$. Implications $p \supset q$ like those in the previous paragraph where the corresponding class $\{\mathrm{q}\}$ is in the interval $[\{\mathrm{p}\},\{\mathrm{T}\}]$ are therefore formally true, and Rutherford marks the difference from material implication by referring to this kind of implication as 'p logically implies q' $(1966,52)$.

Generalising the grouping formed by the affirmation and negation of a single proposition $\mathrm{p}$ to multiple propositions to construct the forms of implication, Piaget, in effect, introduced propositions $\mathrm{q}, \mathrm{r}$, s, etc. from classes in the interval $[\{\mathrm{p}\},\{\mathrm{T}\}]$ of the elementary grouping; $\mathrm{p} \supset \mathrm{q}, \mathrm{p} \supset \mathrm{r}, \mathrm{p} \supset \mathrm{s}$, etc. therefore correspond to classes belonging to $\{\mathrm{T}\}$. The implications in the form of implication above are therefore formally true and, using Rutherford's terminology, $p$ logically implies q, r, s, etc.

Piaget (Piaget and Grize 1972, 15:38-9) also drew attention to an ambiguity in the meaning of the verb 'to imply'. The implication $(p \supset q) \cdot(q \supset r) \rightarrow(p \supset r)$ is true irrespective of the truth or falsity of the individual implications comprising it; the implications $p \supset q, q \supset r$, and $p \supset r$, on 
the other hand, can be true or false depending on the meaning of the propositions $\mathrm{p}, \mathrm{q}$ and $\mathrm{r}$ that comprise them. According to Piaget, the former implication is more formal than the latter since the proposition $\mathrm{p} \supset \mathrm{r}$ is constructed by the conjunction of two other propositions, and he denoted them formal and material implication, respectively. Despite emphasising construction, Piaget appears to have similar distinctions in mind to those in Rutherford's hierarchy of propositions. Moreover, Piaget (Piaget and Grize 1972, 15:226-7 \& 243) also distinguished between operations and relations, and illustrated the difference by contrasting the conditional operator $\mathrm{p} \supset \mathrm{q}$, which is false if $\mathrm{p}$ is true and $\mathrm{q}$ is false, with $\mathrm{pq} \supset \mathrm{p}$, which is true regardless of the propositions substituted for $\mathrm{p}$ and $\mathrm{q}$. Whereas the former is an operation, the latter is a relation because the antecedent and consequent being related ensures that the conditional operator is true without exception. With the aid of the Hasse diagram in Fig. 2, it is easy to see that $p q \supset p$ is formally true. $p[q]$ corresponds to $\{p q \vee \bar{p} q\}$, and, since $\{p q \vee \bar{p} q\}$ is in the interval $[\{p q\},\{T\}],\{p q\}^{\prime} \cup\{p q \vee \bar{p} q\} \in\{T\}$. From the viewpoint of a lattice, an inclusion relation therefore exists between the consequent and antecedent in $p q \supset p$, namely, $\{\mathrm{p}[\mathrm{q}]\} \geqq\{\mathrm{pq}\}$. An inclusion relation between the antecedent and consequent thus appears to capture the distinction between relations and operations made by Piaget. Returning to the form of implication, $\{\mathrm{q}\},\{\mathrm{r}\},\{\mathrm{s}\}$, etc. are in the interval $[\{\mathrm{p}\},\{\mathrm{T}\}]$; the implications $p \supset q, p \supset r, p \supset s$, etc. therefore represent relations rather than operations, namely, $\{q\} \geqq\{p\}$, $\{r\} \geqq\{p\},\{s\} \geqq\{p\}$, etc.

In summary, Piaget constructed deductive operations by introducing propositions from classes in the interval $[\{p\},\{T\}]$. Since $\{p\} ' \cup\{q\} \in\{T\}$ for any such proposition $q$, the implications engendered are formally true; on the one hand, then, formal implications are at play in the forms of implication; on the other hand, $\{\mathrm{q}\} \geqq\{p\} ; p \supset q$ is therefore formally true because there is an inclusion relation between the antecedent and consequent. It is therefore reasonable to conclude that Piaget intended to targeted logical implication in making logic the formal theory of deductive operations.

Before examining how Piaget uses his theory of reasoning to inform logic, it is worth highlighting that relations such as pq $\supset$ p are also known as logical truths. Although there is no consensus on what properties logical truths purportedly possess, the first-person experiences reasoners associate with them-intuitively true, a priori, necessarily true, etc. - traditionally made the strongest case for exceptionalism about logic. On the Piagetian view, however, they are within the scope of a psychological explanation.

\subsection{Psychology as Logical Evidence}

In the previous two sections, formal truth and deductive operations were dealt with separately; however, they cannot remain separate if the logical theory Piaget had in mind is to be a formal theory of deductive operations. To navigate the hazards of psychologism, Piaget used the following compass:

Between the formal theory and the real analysis, there is ... exactly the same relationship as between any axiomatic and any concomitant real research (for example, between axiomatic geometry and the geometry of physical objects): complete independence of methods and possible correspondence of problems (Piaget and Grize 1972, 15:15 my translation) 
The paradoxes of material implication are a problem besetting CL, and Piaget used the method quoted as his compass to chart a passage through the hazards of psychologism to a solution of ex falso quodlibet. Before examining Piaget's approach to this paradox, however, the quotation also reveals how Piaget envisaged a formal theory despite never having actually elaborated one. The comparison with geometry in the quote indicates that Piaget had a system of axioms and rules of inference in mind. His conception of a formal theory is clearly shaped by the axiomatic method, and, like logicians with similar conceptions, Piaget also attached considerable weight to logical truths. ${ }^{4}$ Moreover, Piaget (Piaget and Grize 1972, vol. 15, sec. Inroduction: 4) stressed the importance of the axiomatic style of formalization in banishing extraneous influences on logic, especially those emanating from psychology. Piaget thus associates analyticity in the Fregean sense ${ }^{5}$ with his formal theory.

Before casting off, it is advisable to ensure the vessel is ship-shape and Bristol-fashion. Piaget (e.g., Piaget and Beth 1966, 12:180-1) adopted the tools of propositional calculus, but he adapted them to constructivist ends. Commensurate with practice in propositional calculus, he referred to the binary operator $\supset$ interchangeably as 'implication' or 'conditional'; in this context, 'implication' denotes an operand of the interpropositional grouping. Form I of implications, also, engenders implications; however, 'implication' in this context is a relation in which propositions follow logically from others. The term 'implication' is therefore being used ambiguously, and it would be prudent to disambiguate it before casting off.

In principle, Piaget disambiguated 'implication' by distinguishing between operations and relations, on the one hand, and material and formal implications, on the other; however, he continued to use 'conditional' and 'implication' interchangeably for the operator. To minimise misunderstanding, I will therefore endeavour to refer to the relation exclusively as 'implication' and the operator exclusively as 'conditional' and denote them $\rightarrow$ and $\supset$, respectively. For the remainder of the voyage, then, $p$ implies $q$ will be denoted $p \rightarrow q$, provided there is some relation between $p$ and $q$ ensuring that the conditional operator $p \supset q$ is formally true.

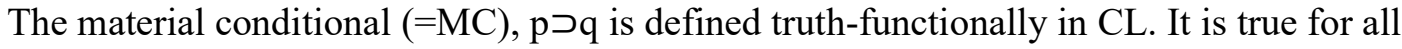
combinations of truth-values of propositions $p$ and $q$ except when $p$ is true and $q$ is false. It can be expressed equivalently in terms of conjunctions, disjunctions and negation as $\bar{p} \vee q$ or $p q \vee \bar{p} q \vee \bar{p} \bar{q}$, and the conjunctive and disjunctive normal forms set out the conditions under which pدq is true. However, validity in CL is purely a matter of form, and, since the relevance of antecedents and consequents in $\mathrm{MC}$ is not a formal requirement, it is possible to find substitutions that are counterintuitive. If $q$ is true or $p$ is false, for example, the exception is automatically ruled out, and MC must be true. Since $q \supset(p \supset q)$, positive paradox, and $\mathrm{p} \supset(\overline{\mathrm{p}} \supset \mathrm{q})$, ex falso quodlibet, satisfy these formal requirements, they are valid formulae in CL; however, inferences from a true statement like 'I am alive' to 'if I am dead, I am alive' or 'if I'm not alive, I'm famous/everyone is happy/everyone is sad/etc. ${ }^{6}$ are intuitively false.

\footnotetext{
${ }^{4}$ Piaget was not well acquainted with contemporary developments in mathematical logic (Grize 2013, 149)

${ }^{5}$ Shapiro $(2000,108-9)$ draws attention to changes in the meaning of 'analyticity' introduced by Frege and I use the term here in this sense.

${ }^{6}$ The examples come from (Restall 2006, 65)
} 
'Paradox' has a variety of meanings (Quine 1966). Although they represent a mismatch between the $\mathrm{CL}$ account of $\mathrm{MC}$ and intuition rather than contradictions from valid reasoning, the formulae are nevertheless known collectively as paradoxes of material implication. Moreover, the mismatch is due to counterintuitive examples satisfying valid formulae in CL. In terms of the mirror metaphor Piaget used to express the relationship between a logic and thought, CL does not reflect some forms of counterintuitive reasoning. In other words, there are blind spots in the mirror.

Acceptance and denial broadly characterise positions on the mismatch. Those in denial are obliged to explain, or explain away, the paradoxes whilst accepting that CL adequately reflects reasoning whether it be transacted in the formal language of mathematics or the vernacular. Those accepting the mismatch, on the other hand, often point out that CL was not developed for reasoning transacted in the vernacular but for mathematical reasoning, and the paradoxes of MC are the result of misappropriation. However, it is considered to be the mark of a good theory that its explanatory power exceeds, sometimes by far, the limited field of phenomena initially investigated - one only has to call to mind the regularities in free-falling bodies discovered by Galileo on the basis of crude observations and the role they played in explaining terrestrial and planetary motions in Newton's hands (e.g., Wigner 1960). However, the positions are only 'broadly' as black-and-white as I have portrayed. Gabbay and Woods (2005, sec. 1.4) draw attention to the conciliatory tones struck, especially by those accepting the mismatch.

Formalisation in CL is the process of finding the CL counterparts of reasoning transacted in the vernacular. It maps vernacular structures into logical forms in CL in such a way that the property possessed by the logical form formalising the vernacular structure in CL reflects backwards onto the vernacular itself. Consequently, if a structure of CL formalising a vernacular structure has certain logical properties, the vernacular structure formalised does too. The central principle governing formalisation of the vernacular in CL is known as backwards reflection, and the following truth-conditional relationship obtains for the connectives: the falsity of the formalisation of the vernacular sentence is sufficient for the falsity of the vernacular sentence but not conversely, and the truth of a sentence in either the vernacular or its formalisation is not sufficient for the truth of the corresponding sentence. In other words, the mirror has a special polish due to the principle of backwards reflection, in which vernacular sentences and their formalisation in CL are not logically equivalent, let alone synonymous, and counterintuitive reasoning in the vernacular is not always reflected.

From an operatory viewpoint, on the other hand, the propositions $\mathrm{p}$ and $\mathrm{q}$ in $\mathrm{p} \supset \mathrm{q}$ are related in such a way that pq, $\bar{p} q$, and $\overline{p q}$ are true whereas $p \bar{q}$ is not true. In $\bar{p} \supset q$, on the other hand, $\bar{p} q, p q$, and $p \bar{q}$ whereas $\overline{p q}$ is not true. Since $\overline{p q}$ is true in $p \supset q$ but cannot be true in $\bar{p} \supset q$ and $p \bar{q}$ is true in the latter but cannot be true in the former, $p \supset q$ and $\bar{p} \supset q$ are incompatible from an operatory point of view; consequently, Piaget (Piaget and Grize 1972, 15:244) objected vehemently to paraphrasing ex falso quodlibet as 'the false implies the true'. From an operatory point of view, $\mathrm{p}$ can be false when $\mathrm{q}$ is true in the conditional operator but that does not mean that the false implies the true. The problem, according to Piaget, boils down to understanding how $\bar{p} q$ can be true whilst $p \bar{q}$ cannot in the conditional operator.

In Piaget's rational reconstruction of the genesis of the interpropositional grouping, extending the elementary grouping to multiple propositions by introducing new propositions in the 
interval $[\{\mathrm{p}\},\{\mathrm{T}\}]$ excludes the possibility that the antecedents of the conditionals constructed are true and the consequents false. For $q=p \vee p$, for example, $p$ is included in $q$ (see Fig. 2), and the truth of $p \bar{q}$ is excluded in this construction; however, the truth of $p$ ' $=\bar{p} q$ is not. The form of implication thus illustrates a construction in which $\bar{p} q$ can be true whilst $p \bar{q}$ is definitely false.

However, simply excluding $p \bar{q}$ from being true is not sufficient to ensure that the relationship between the propositions $\mathrm{p}$ and $\mathrm{q}$ is in fact $\mathrm{p} \supset \mathrm{q}$. Referring to Table $1, \mathrm{p} \overline{\mathrm{q}}$ is false in eight of the logical operators; excluding $p \bar{q}$ thus narrows down the number of operators by half; however, the shortlist is not yet short enough since a whole host of candidates still cannot be ruled out. Besides $\mathrm{p} \overline{\mathrm{q}}$ being false, the truth of the conjunctions $\mathrm{pq}, \overline{\mathrm{p} q}$ and $\overline{\mathrm{pq}}$ must also be taken into account. From an operatory point of view, $\mathrm{p} \supset \mathrm{q}$ is a distinct logical operator among the 16 operands of the interpropositional grouping involving two propositions, and it is uniquely determined by the truth of all three conjunctions as well as the falsity of $\mathrm{p} \overline{\mathrm{q}}$. In CL, in contrast, $\mathrm{pqV} \overline{\mathrm{p} q \vee \overline{p q}}$ is the characteristic form of the conditional, and it is true when any of these conjunctions is true; in fact, the conjunctions are incompatible in CL and cannot therefore be true simultaneously. Moreover, conjunction, equivalence and the conditional have pq in common, and the conditional also has $\overline{\mathrm{pq}}$ in common with the equivalence. Discriminating conjunctions, equivalences and conditionals is thus not always possible in CL, although they are distinct operands of the interpropositional grouping. In other words, the polish of CL as a mirror does not adequately reflect the conditional operator as a distinct operand of the interpropositional grouping.

The formal theory of the conditional $\mathrm{p} \supset \mathrm{q}$ as a deductive operation has to fulfil two conditions to be an adequate reflection: on the one hand, the truth of $p \bar{q}$ has to be excluded for $p \supset q$ to be a deductive operation; on the other hand, the conditional, even as a deductive operation, is still a distinct operand of the interpropositional grouping, and the formal theory must also reflect this fact. The truth of $\bar{p} q$ is sufficient to distinguish the conditional $p \supset q$ from both conjunction and equivalence, and, according to Piaget, it is key to delineating the reflections of the conditional, conjunction and equivalence in the formal theory. Implication should therefore be a ternary rather than a binary expression according to Piaget (Piaget and Grize 1972, 15:245-6):

$\mathrm{p} \rightarrow \mathrm{q}$ means $(\mathrm{p} \rightarrow \mathrm{q}) \cdot\left(\mathrm{p}^{\prime} \rightarrow \mathrm{q}\right)$ where $\mathrm{p}^{\prime} \leftrightarrow \overline{\mathrm{p}} \cdot \mathrm{q}^{7}$

Piaget (Piaget and Grize 1972, 15:246) also expressed implication as follows:

$\mathrm{p} \rightarrow \mathrm{q}$ therefore $\mathrm{q} \leftrightarrow\left(\mathrm{p} \vee \mathrm{p}^{\prime}\right)$,

and he held both expressions to be equivalent. Referring back to the Hasse diagram in Fig. 2, for $\{\mathrm{q}[\mathrm{p}]\}=\{\mathrm{pq} \vee \overline{\mathrm{p}} \mathrm{q},\{\mathrm{q}[\mathrm{p}]\} \geqq\{\mathrm{pq}\}$ and $\{\mathrm{q}[\mathrm{p}]\} \geqq\{\overline{\mathrm{p}} \mathrm{q}\}$ but not $\{\mathrm{pq}\} \geqq\{\mathrm{q}[\mathrm{p}]\} ; \mathrm{pq} \supset \mathrm{q}[\mathrm{p}]$ and $\bar{p} q \supset q[p]$ are therefore formally true, i.e., $p q \rightarrow q[p]$ and $\bar{p} q \rightarrow q[p]$. On condition $q \in[\{p\}$ ', $\{\mathrm{T}\}$ ], which is the case in the forms of implication, the different formulations thus represent alternative expressions.

Ex falso quodlibet is by no means the only paradox besetting CL, and in 'Paradoxes of Material Implication - a Piagetian Perspective', I extend Piaget's approach to further

${ }^{7}$ Like $\mathrm{p} \rightarrow \mathrm{q}$ and $\mathrm{p} \supset \mathrm{q}, \mathrm{p} \leftrightarrow \mathrm{q}$ denotes the formal truth of the logical operator $\mathrm{p} \equiv \mathrm{q}$. 
paradoxes. In Piaget's theory of propositional reasoning, the conditional operator is a distinct operand of the interpropositional grouping uniquely determined by $p q, \bar{p} q$, and $\overline{p q}$ being true and $p \bar{q}$, false. In $C L$, on the other hand, the characteristic form $p q \vee \bar{p} q \vee \overline{p q}$ represents the truthconditions of MC; however, only one of these conjunctions can be true in $\mathrm{CL}$, and $\mathrm{MC}$ is true when one of them is true. On the basis of a single conjunction of MC's characteristic form, however, the conditional operator of the interpropositional grouping is not uniquely determined. Several distinct logical operators of the interpropositional grouping correspond to each conjunction of the characteristic form of MC in CL; CL cannot therefore adequately reflect the conditional operator as a distinct operand of the interpropositional grouping. In other words, the conditional operator as a distinct operand of the interpropositional grouping is not reflected backwards by CL and is therefore not an adequate formalisation of Piaget's theory of reasoning.

Piaget highlighted $\overline{\mathrm{p}} \mathrm{q}$ as being key in delineating $\mathrm{p} \supset \mathrm{q}$ from other deductive operators and substituted a ternary operator involving $p, p^{\prime}=\bar{p} q$ and $q$ for a binary operator in CL to take this into account. As already mentioned, Piaget did not fully develop a logical theory based on his psychological theory of reasoning, but an ad hoc amendment of CL can be ruled out because the conjunctions uniquely characterising any logical operator of the interpropositional grouping are incompatible in CL and therefore cannot be true simultaneously. The crux of the problem seems to be that a logical theory must take into account the fact that logical operators are involved in reasoning and therefore already parts of a natural structure. Intuitively, logic is an integral part of reasoning, and deductive operations are an integral part of the interpropositional grouping in Piaget's theory of reasoning. Although Piaget never actually formulated a logical theory, he cut a factual key to open a door on this intuition. Moreover, a logical theory of deductive operations based on logical implication as the corresponding logical property seems to be a viable proposition in the light of lattice theory. Be that as it may, the fact that Piaget used a psychological theory of reasoning to diagnose and suggest a credible solution to a logical problem is salient for the present purposes since it illustrates how psychology can serve as evidence for a logical theory.

\section{Exceptionalism vs Anti-Exceptionalism in Light of Psychology as a Source of Logical Evidence.}

\subsection{The Dogma of Psychologism, a Case for Anti-exceptionalism}

Since Frege's criticism of psychologism, psychology and logic have gone their separate ways. In theory, Piaget respected the strict division of labour. Developmental psychology à la Piaget explains the emergence of operational structures by describing the development of operations of thought in states of equilibrium from their origin in the most elementary coordinations of actions on arbitrary objects. In equilibrium, operations of thought form wellstructured systems of operations, which psycho-logic models using algebraic tools. The psychological theory of reasoning is therefore a causal explanation of our ability to reason, and it has synchronic and diachronic aspects. On the other hand, Piaget contrasted ordinary truth with formal truth, the former referring to the correspondence between the constructs of the mind and the subject matter targeted; the latter referring simply to the coherence, agreement, implication and exclusion of propositions, etc. without concern for their actual truth. Formal truth characterises logic, according to Piaget, and he advocated the axiomatic method for logic in order to purify it of extraneous influences such as folk psychology. He 
thereby distinguished between logical and substantial axiomatizations. The grouping models the structured wholes operations of thought in a state of equilibrium constitute. Since it corresponds to psychological facts, it is thus a substantial axiomatization despite its formal appearance. An axiomatization of logic, in contrast, is a formal system, in which formulae are derived from others postulated as axioms using rules of inference. Although Piaget did not set out a logical theory, his characterization of logic is commensurate with accepted logical properties, and it conforms with the axiomatic tradition initiated by Frege.

The division of labour Piaget advocated corresponds to one GER Lloyd developed to capture the perspectivism of historical research. Lloyd (2007, nn. 2, 3 pp. 6-7; 2010, 204-5) introduces the 'multidimensionality of phenomena' and corresponding 'styles of inquiry'. With the former he counters the temptation to maintain that there is only one mode of inquiry yielding accurate results for any scientific subject matter by pointing out that phenomena invariably have many different aspects, which can be brought to light by appropriate modes of inquiry; however, none of these aspects is inherently more correct than any other. By the latter, Lloyd means the various methods, procedures and equipment used in diverse areas of scientific research to discover, engender or even create the subject matter under investigation. Interpropositional operations as Piaget understands them are clearly multidimensional mental phenomena. On the one hand, formal truth characterizes logic, and the interpropositional operations of the grouping have a relationship to truth via the propositions they operate on. The style of inquiry commensurate with the truth dimension of interpropositional operations focusses on the typical subject matter for logical theories, namely coherence, validity, truth preservation, provability, etc. On the other hand, interpropositional operations also have a psycho-sociological aspect, and the appropriate style of inquiry is causal explanation. For Piaget, the causal explanation is diachronic and synchronic, the former explaining by describing the development of the equilibria operations of thought from their origins in coordination of actions on arbitrary objects and the latter by modelling the structured wholes operations of thought form in the states of equilibrium.

In theory, Piaget demarcated different dimensions of interpropositional operations and their styles of inquiry; however, he also used the psychological dimension to shed light on a logical problem, namely, ex falso quodlibet. In practice, then, he did not consider the dimensions to be orthogonal. Piaget expressed the relationship between the dimensions metaphorically as logic mirroring thought; however, he did not hide behind a metaphor. Logic is the formal theory of deductive operations, according to Piaget, and based on this formula, he used independence of methods but possible correspondence of problems as his compass to navigate the hazards of psychologism. Charting this course, he diagnosed the problem in this paradox to be the definition of MC in CL not always adequately reflecting the fact that the conditional operator is a distinct operand in the interpropositional grouping. His resolution of the paradox is then based on this insight; however, it cannot be interpreted as a simple ad hoc augmentation of CL. On the one hand, Piaget's logical theory targeted a proposition cubed not squared, i.e., logical rather than material implication. Whilst an extension of CL could accommodate logical implication, the conjunctions of the characteristic form of MC in CL are incompatible and cannot therefore be true simultaneously as they are in the conditional operator of the interpropositional grouping. It is thus doubtful that extensions of CL could ever accurately reflect logical properties inherent in 
the interpropositional grouping; ${ }^{8}$ nevertheless, there is to my mind no reason why psychology thus understood cannot serve as a source of logical evidence for a logical theory.

Science is a social endeavour, and the sociology of knowledge has revealed many external factors influencing its development (e.g., Kuhn 1960; Barnes 1977; Shapin 1982; Collins 1983; Shapin 2008). The fact that psychology could be but is not generally countenanced as a source of logical evidence for logical theories seems to me to be due to external rather than internal factors. Logic long enjoyed an exceptional status; however, a cursory glance at typical arguments against psychologism (e.g., Jacquette 2003a, sec. 4) reveals that they are designed to defend many of those qualities purportedly conferring logic an exceptional status. Admitting any dependency on the findings of psychology would thus be tantamount to surrendering logic's exceptional status - how Ancient-Greek cosmology made astronomy go round in circles until Johannes Kepler springs to mind. Psychologism is embroiled in the exceptionalism/anti-exceptionalism discourse and will surface in subsequent discussion. Be that as it may, the accusation of psychologism became a dogma damning logical theories suspected of psychological inclinations with an almost inquisitional zeal; there are, however, voices in the desert: those who wish to rekindle debate and redress the imbalance by encouraging a more discerning approach to psychologism (Jacquette 2003a, secs. 2-4; Gabbay and Woods 2005; van Benthem 2008; Stenning and van Lambalgen 2008).

The accusation of psychologism is an idiosyncrasy of logic; however, similar controversies are typical of science in general, and I concur with Martin and Hjortland:

neither the problem of what exactly ought to constitute evidence for a logical theory, nor how we ought to select and weight theoretical virtues within a theory-choice, are particular to logical epistemology. While both questions are worthy of discussion, the disagreements that inevitably flow from asking them are no more an indication of a fatal flaw with the anti-exceptionalist account of logic than abductivist methodologies within other research areas. These are issues not specific to logic, but concerns raised over theory-choice more generally. In facing these problems then, logical methodology is again not exceptional. (Martin and Hjortland 2021, sec. 5)

\subsection{Tertium Quid}

If psychologism did prejudice the development of logical theories against using psychology as a source of logical evidence, scope may exist for a logical theory that accommodates the findings of psychology. Perhaps because epistemology was his primary research interest, Piaget never, to my knowledge, actually set out the details of such a logical theory (Apostel 1982; Grize 2013). Nevertheless, some insights can still be garnered on the basis of the indications he has given.

Although the properties logical truths purportedly possess are contentious, they have undoubtedly contributed in some measure to the exceptional status attributed to logic. Piaget distinguished between operations and relations on the one hand and formal and material implication on the other. Since both relations and formal implications are formally true, they

\footnotetext{
${ }^{8}$ In 'Paradoxes of Material Implication - a Piagetian Perspective', I also conclude that CL and Piaget's logical theory would constitute rival logical theories.
} 
would qualify as logical truths. However, relations are formally true, according to Piaget, because the propositions involved in the logical operator are related; formal implication on the other hand because of a prior construction. At first blush, the grounds for them being formally true are different; however, the forms of implication mediate between these explanations. On the one hand, the form of implication illustrated in Fig. 1 is a construction, and the implications engendered are formally true; on the other hand, there is also an inclusion relation between the antecedent and consequent. From a Piagetian perspective, then, prior constructions constitute relations. Moreover, the constructions in question originate in operations of thought, and operations of thought originate in the co-ordinations of actions on arbitrary objects; logical truths on this view therefore have roots in the activity of the subject.

Empiricists traditionally regarded sense experience as the only source of knowledge. Rationalists, on the other hand, argued against the empirical origin of logical truths by drawing attention to the exceptional properties they purportedly possess. The strength of empiricism lies in its ability to explain how thought fits fact, but it struggles to explain the exceptional properties of logical truths; for rationalism, on the other hand, the strengths and weakness are reversed. However, with constructivism as an alternative explanation for the exceptional properties of logical truths, an argument against empiricism cannot be automatically construed as an argument for rationalism. On the other hand, empiricists, those at least who believe sense experience to be the source of logical truths, have little to gain from rationalism's setback because logical truths, being constructions, originate in the activity of the subject rather than sense experience. For Piaget constructivism is a tertium quid:

the operational constructivism suggested by genetic analysis is reduced neither to empiricism nor to apriorism, because we could not derive intelligence itself from objects ... and because the subject does not possess frameworks which contain all reason in advance, but only a certain activity which allows him to construct operational structures. (Piaget and Beth 1966, $12: 285)$

Regarding logical truths as constructions has ramifications for exceptionalism and antiexceptionalism on logic. Just as the senses are required to perceive the empirical world, logical truths being different from empirical truths were thought to require their own special mental faculty for grasping them. From the viewpoint of constructivism, however, logical truths are also a priori, but they are constructed rather than being preformed. Moreover, construction is all that is required to grasp them. Of course, the subjective reconstruction of denizens populating another realm is consistent with a priori truths not appearing to be preformed, and metaphysical realism cannot be ruled-out entirely. However, from a constructivist point of view, it a redundant hypothesis since construction confers consciousness and no special cognitive faculty other than construction is evident.

In summary, a logical theory à la Piaget would be continuous with psychology, and it would therefore be revisable on the basis of a posteriori evidence derived from a psychological theory of reasoning. Logical truths, on the other hand, would be a priori in the sense that they can be grasped without the aid of the senses; however, they would not constitute a preformed reality requiring a special mental means to grasp them; construction would be sufficient. 
Constructivism thus weakens exceptionalism by integrating the purportedly exceptional properties of logical truths into a psychological explanation.

However, there is a reverse side to every medal, and constructivism inherits problems either empiricism or rationalism purportedly solved. Psychology is descriptive; logic on the other hand is thought to be prescriptive. The transition from description to prescription thus becomes a conundrum for a logical theory that is continuous with psychology. Moreover, logic looks out for other forms of knowledge but not vice versa. Logic has to look out for itself, but without a special means of grasping apodictic truths it is hard to vouch for this exceptional ability. On the other hand, logic is an essential tool for all sciences and can accommodate all manner of phenomena; however, logic being adapted to all manner of phenomena constitutes as much a riddle for constructivism as it does for rationalism. On the one hand, explaining a mind-independent reality, even aspects as fundamental as causality, is only possible by means of the structures of operations of thought. Whilst ensuring a logical theory based on constructivism is immune to empirical falsification, it is of no assistance in explaining how a logical theory is fit for this job. On the other hand, operations of thought originate in the activity of the subject, namely, the coordination of actions on arbitrary objects; they do not therefore even have roots in the properties of the mind-independent reality they help to describe and explain. In short, the fit of thought and fact is as much a problem for constructivism as rationalism, and the prescriptivity and basicness of logic as much a problem for constructivism as empiricism.

\subsection{Genetic Epistemology and the Challenges facing Anti-Exceptionalism}

There are problems with anti-exceptionalism about logic, which arise from rejecting rationalism. For example, there is no consensus amongst logicians on the role logic should play: some argue that logic only has a descriptive role to play whilst others hold that it should improve or replace vernacular judgements (Martin and Hjortland 2021, sec. 5). In other words, logic is thought not only to be descriptive but also prescriptive. Moreover, even logical theories that are descriptive are not indiscriminate concerning what counts as logical evidence. Priest (2016, sec. 2.5), for example, considers natural-language intuitions to be a source of logical evidence; however, they have to be 'robust' (Priest 2016, 44). He accepts that these intuitions are subject to systematic performance errors, and, although mistakes can easily be recognized and purged when highlighted, the upshot is that natural-language intuitions are not infallible and judgement is required to separate the sheep from the goats. ${ }^{9}$

Comparing laws of truth with laws of nature, Frege (1998, 32:XV) drew attention to the descriptive and prescriptive aspects of both. The law of gravity does not just describe how objects have fallen to earth but how they fall, thereby dictating how we should think about falling objects. Psychologically, judgements have causal explanations, but there is no scope for normative evaluations on the basis of causality alone. The different rates at which objects actually fall to Earth also have causal explanations, but it would not be possible to maintain that the rate of fall is better approximated by a lead sphere than a feather without reference to

\footnotetext{
${ }^{9}$ Referring to natural language intuitions as a source of logical evidence, Priest $(2016,44)$ requires them to be robust; i.e., purged of performance errors. However, there is no independent criteria for their robustness; the people making the mistakes simply recognised them when the error is pointed out.
} 
the law of gravity. Analogously, it is not possible to assess whether reasoning is correct or not on the basis of causality alone.

In psychology, competence and performance are distinguished (e.g., Flavell and Wohlwill 1969; Overton and Newman 1982). The distinction is much like that between genotype and phenotype in biology. The genotype refers to the part of the genetic code offspring inherit from their parent organisms; the phenotype, on the other hand, refers to the physical and behavioural traits. The genotype generates the phenotype but not conversely. The genotype is only affected by the phenotype indirectly insofar as survival and mating and therefore the transmission of the genetic code from one generation to the next depends on phenotypical traits. Although the structured wholes operations of thought in a state of equilibrium form are not inherited, they distinguish competence from performance just as the genetic code distinguishes the genotype from the phenotype. The interpropositional grouping, in particular, corresponds to competence in propositional reasoning, and it determines the type of reasoning tasks reasoners with this level of competence should be able to master; actual performance on the other hand is situative, and many factors may contrive to cause reasoners to reason below par. Nevertheless, Piaget's theory of reasoning is both descriptive and prescriptive because reasoning competence is distinct from performance and no more a theoretical fiction than the law of gravity. Moreover, a logical theory adequately reflecting the operations of thought in a state of equilibrium, although not causal itself, would reflect competence and would therefore not only be descriptive but also prescriptive with respect to actual performance. ${ }^{10}$

Finally, logic and mathematics are thought to be distinct despite both being a priori, from the viewpoint of exceptionalism. They are both indispensable to science; however, mathematics can still appeal to logic to derive its theories whereas logic can only look to itself. In the absence of special logical faculties, choice of a logical theory must be based on rational grounds; however, the validity of any argument is based on a logical theory. Hence a logical theory either undermines its own justification if the arguments used are not supported by the theory or the arguments supporting the theory are supported by the theory. However, in the latter case, logical theories are self-justifying, and preferences for one theory over another are arbitrary from a logical point of view. In essence, the problem is circularity (Priest 2016, sec. 3.4), and Martin and Hjortland coined the expression 'background logic problem' (Martin and Hjortland 2021, sec. 5) to denote it.

The background logic problem was the original motivation for the exceptionalism of logic, and it still poses the strongest challenge for anti-exceptionalism, according to Martin and Hjortland (2021, sec. 5). Rather than being the greatest challenge, however, the background logic problem may actually be its strongest ally.

Although it is widely accepted now that empirical evidence is theory-laden, theory and evidence are still thought to spring ultimately from different sources, and the adequacy of a scientific theory is measured by its correspondence with empirical evidence. In the human sciences, the sources are not always distinct. Reasoning is a case in point. Mathematics, the sciences, juris prudence, even the vernacular, etc., are sources of inference, which can

\footnotetext{
${ }^{10}$ Piaget (Piaget and Grize 1972, 15:7-8) comes to the same conclusion about logic but by considering logic itself.
} 
become objects of study. However, assessing such arguments and inferences from the point of view of rationality relies on the very capacity that generated them in the first place.

Following Gabbay and Woods (Gabbay and Woods 2005, sec. 2), for example, cognitive systems are comprised of a cognitive agent, cognitive resources, as well as a cognitive agenda executed in real time, and reasoning in practice is constrained accordingly by agents' agendas, competence, and the resources at their disposable. Cognitive systems can be individuals or institutions, and they can be partially ordered according to the cognitive resources at their command relative to the cognitive goals aspired to. The performance of individual reasoners is a modest affaire, far from being infallible but right enough enough of the time. Having substantially more resources at their disposal, research communities on the other hand are more ambitious, and, by pooling their resources, they can eliminate performance errors in aspects of reasoning thus producing robust results. Using Gabbay and Wood's denotation, the former are practical agents whereas the latter are theoretical agents, and theoretical agents can achieve all the goals practical agents can, while the latter may not have the resources to aspire to and attain the same goals as the former. Nevertheless, practical agents acknowledge, perhaps on authority, the robust results of theoretical agents. Whilst practical agents can defer to theoretical agents, reasoning is still executive and judiciary for the latter, and a circularity similar to the background logic problem arises. Moreover, consensus rather than correspondence is the criterion of robustness. ${ }^{11}$

Although perhaps more obvious in the human sciences, circularity is not thought to be confined to them. Discussing William Alston's work on epistemic circularity, Lammanranta (2018, sec. 1) claims that any source of knowledge when interrogated to the utmost ends up in a circle. Arguing that perceptual evidence is a reliable source of knowledge, for example, one could proceed inductively by listing past instances of perception being reliable evidence. However, when asked to justify belief in each instance of perception being reliable, one is forced to resort to the conclusion, namely, that perception is a reliable source of knowledge. In other words, justification of belief in the conclusion requires evidence, but belief in the evidence is justified by the conclusion. Seen in the context of science in general, the background logic problem is thus a problem of circularity that logic shares with other sciences. Moreover, even intuition if quizzed on its reliability as a special source of logical evidence would not escape epistemic circularity. Rather than revealing an exceptional feature of logic, then, the background logic problem is an additional argument for antiexceptionalism.

Of course, the main concern is not circularity per se but whether the circle is vicious. Epistemic circularity is not thought to be vicious; however, it is not discriminating (Lammenranta 2018, sec. 1) - much like logical theories. Piaget (1950a, vol. 1, sec. Introduction 6) also considered knowledge to be circular, but he did not believe that epistemic circularity is necessarily vicious. In practice, the sciences cope with the inherent circularity of attaining knowledge on the basis of beliefs by expanding the scope of any theory so that convergence in the growing coherence of its propositions warrants belief in the circularity not being vicious. Logic as a formal theory of deductive operations of thought, for example, would integrate logic into the structuralism of genetic psychology, on the one hand,

\footnotetext{
${ }^{11}$ According to Priest (2016, 40-1), logic is a social science; theory and subject matter in logic may not therefore enjoy the same independence as in the natural sciences.
} 
and, via Boolean algebra, into the structures of mathematics, on the other (Piaget 1970, sec. 7). Returning to the present context, it will be recalled that psychological explanations according to Piaget have two aspects, and the analogy with falling objects helps show how these aspects can be seen to converge and support each other mutually. Phenomenally, objects of all shapes and sizes falling in Earth's atmosphere do not actually fall according to the gravitational law; analogously, the practical agent is far from being infallible when reasoning but right enough enough of the time. However, any object regardless of shape and size really does begin to fall increasingly in accordance with the law of gravity as the atmosphere is progressively rarefied. Analogously, as theoretical agents take the reins from their practical counterparts and generate increasingly robust results, performance approximates to competence. The crowded scrutiny of communities of researchers is thus for the investigation of reasoning what the void is for free falling bodies. According to Piaget (e.g., Piaget 1950b, vol. 3, chap. VII sec. 7), objectivity is intersubjective objectivity; Piaget therefore also developed a sociological theory of reasoning, which he based on his psychological theory of reasoning (Kitchener 1996; Kitchener 2004; Kitchener 2009). However, just as freefall in a vacuum would be just one phenomenon amongst many without the law of gravity, the consensus of theoretical agents might be indistinguishable from conventions and coercions of the crowd without a theory of reasoning. On this view, 'theoretical agent' turns out to be a particularly apt terminology since it is the means through which the interpropositional grouping imminent in reasoning and therefore the psychological theory of reasoning itself manifests most purely in practice. Be that as it may, logic does not only have circularity in common with the other sciences but it can only allay its own circularity in conjunction with the other sciences: on the Piagetian view, namely, the virtuosity of the circle vouches for it not being vicious. Logic is thus far from being exceptional on account of the background logic problem, and it is as dependent on the other sciences to solve this problem as they are on it.

Piaget's constructivism weaves logic into a web of beliefs like more contemporary forms of empiricism; logic is therefore substantiated indirectly by the victories of the empirical sciences that cannot do without it. Nevertheless, logic does not hang by a thread from the empirical sciences, content to celebrate its own standing vicariously in victories of the latter. Logic is a thread like any other woven into the fabric of a scientific worldview, making its humble contribution to the quality of the cloth. However, the fabric remains flawed. Logic originates in the activity of the subject according to constructivism; despite finding comfort in its coherence with empirical sciences, then, constructivism does not explain the fit of logic and fact like traditional empiricism.

\section{In Balance}

Piaget envisaged a logical theory based on a psychological theory of reasoning. Although he never formulated the logical theory in any detail, it was supposed to mirror deductive operations of thought. He did, however, appeal to his psychological theory of reasoning to diagnose and suggest a solution to ex falso quodlibet, thus illustrating how psychology can serve as a source of logical evidence for a logical theory. Piaget's logical theory would be continuous with psychology, and like other scientific theories its development would be subject to external factors. Being a reflection of a psychological theory of reasoning, Piaget's logical theory would also presumably be subject to revision as new psychological evidence comes to light. The constructivism inherent in Piaget's psychological theory of reasoning 
explains the a priori nature of logical truths without recourse to a special mental means of grasping them, thereby undermining the strongest argument for exceptionalism about logic. However, constructivism cannot capitalise on the traditional empiricist explanation for the fit of thought and fact since logical truths originate in the activity of the subject. Nevertheless, constructivism seems to cope well with the greatest challenges anti-exceptionalism about logic has to face. On the one hand, the strict demarcation of logic and empirical sciences along the lines of prescription and description appears to be an exaggeration. On the other hand, the background logic problem is symptomatic of the circularity imminent in all scientific knowledge. Moreover, a logical theory cannot solve the problem of circularity alone; it must join forces with the other sciences to determine whether the circularity is vicious or not. In balance, basing a logical theory on the evidence of a psychological theory of reasoning as Piaget indicated appears to be feasible, and it would appear to make an exceptionally strong case for anti-exceptionalism.

\section{References}

Apostel, Leo. 1982. The Future of Piagetian Logic. Revue Internationale de Philosophie 36: 567-611.

Barnes, Barry. 1977. Interests and the Growth of Knowledge. New York: Routledge.

van Benthem, Johan. 2008. Logic and Reasoning: Do the Facts Matter? Studia Logica 88: 67-84. https://doi.org/10.1007/s11225-008-9101-1.

Bond, Trevor G. 1978. Propositional Logic as a Model for Adolescent IntelligenceAdditional Considerations. Interchange 9: 93-98. https://doi.org/10.1007/BF01816518.

Bond, Trevor G. 2005. Piaget and Measurement II: Empirical Validation of the Piagetian Model. In Critical Readings on Piaget, ed. Leslie Smith, ebook, 178-208. Routledge.

Collins, Harry. 1983. An Empirical Relativist Programme in the Sociology of Scientific Knowledge. In Science Observed: Perspectives on the Social Study of Science, ed. Karin Knorr-Cetina and Michael Mulkay, 115-140. London: Sage Publications, Inc.

Flavell, John H., and Joachin F. Wohlwill. 1969. Formal and Functional Aspects of Cognitive Development. In Studies in Cognitive Development: Essays in Honor of Jean Piaget, ed. David Elkind and John H. Flavell, 67-120. Studies in Cognitive Development. Oxford University Press.

Frege, Gottlob. 1993. Der Gedanke: Eine Logische Untersuchung. In Logische Untersuchungen, 4., durchges. und bibliographisch erg. Aufl., 1219:30-53. Kleine Vandenhoeck-Reihe. Goettingen: Vandenhoeck und Ruprecht.

Frege, Gottlob. 1998. Grundgesetze der Arithmetik begriffsschrifftlich abgeleitet. 2. Nachdr. d. Ausg. Jena 1893-1903. Vol. 32. Olms-Paperbacks. Hildesheim: Olms.

Gabbay, Dov M., and John Woods. 2005. The Practical Turn in Logic. In Handbook of Philosophical Logic, ed. Dov M. Gabbay and F. Guenthner, 2nd ed., 13:15-122. Handbook of Philosophical Logic. Dordrecht: Springer-Verlag. https://doi.org/10.1007/1-4020-3521-7_1.

George, Rolf. 1997. Psychologism in Logic: Bacon to Bolzano. Philosophy \& Rhetoric 30: 213-242.

Grize, Jean-Blaise. 2013. Operatory Logic. In Piaget Today, ed. Baerbel Inhelder, Denys de Caprona, and Angela Cornu-Wells, electronic resource, 149-64. Psychology Revivals. Taylor and Francis.

Haack, Susan. 1978. Philosophy of Logics. London, New York, Melbourne: Cambridge University Press. 
Haase, Matthias. 2009. The Laws of Thought and the Power of Thinking. Canadian Journal of Philosophy 35: 249-297. https://doi.org/10.1080/00455091.2009.10717650.

Halmos, Paul R., and Steven Givant. 1998. Logic as algebra. Vol. 21. The Dolciani Mathematical Expositions. Washington D. C: The Mathematical Association of America.

Hanna, Robert. 2006. Rationality and Logic. Cambridge Massachusetts; London England: MIT Press.

Hjortland, Ole Thomassen. 2017. Anti-Exceptionalism about Logic. Philosophical Studies 174: 631-658. https://doi.org/10.1007/s11098-016-0701-8.

Hjortland, Ole Thomassen. 2019. What Counts as Evidence for a Logical Theory? The Australasian Journal of Logic 16: 250-282. https://doi.org/10.26686/ajl.v16i7.5912.

Inhelder, Baerbel, and Jean Piaget. 1969. The Psychology of the Child. Translated by Helen Weaver. New York: Basic Books.

Jaakko, Hintikka, and Gabriel Sandu. 2007. What is Logic? In Philosophy of Logic, ed. Dale Jacquette, 13-40. Handbook of the Philosophy of Science. Netherlands: North Holland.

Jacquette, Dale. 1997. The Dialectics of Psychologism. Philosophy \& Rhetoric 30: V-VIII. Jacquette, Dale. 2001. Psychologism Revisited in Logic, Metaphysics, and Epistemology. Metaphilosophy 32: 261-278. https://doi.org/10.1111/1467-9973.00187.

Jacquette, Dale. 2003a. Introduction: Psychologism the Philosophical Shibboleth. In Philosophy, Psychology, and Psychologism, 1-19. Philosophical Studies Series. Springer, Dordrecht. https://doi.org/10.1007/0-306-48134-0_1.

Jacquette, Dale, ed. 2003b. Philosophy, Psychology, and Psychologism: Critical and Historical Readings on the Psychological Turn in Philosophy. Vol. 91. Philosophical Studies Series. New York, Boston, Dordrecht, London, Moscow: Kluwer Academic Publishers.

Jacquette, Dale. 2007. Introduction: Philosophy of Logic Today. In Philosophy of Logic Today, ed. Dale Jacquette, 1-12. Handbook of the Philosophy of Science. Netherlands: North Holland.

Johnson-Laird, Philip N. 2006. How We Reason. USA: Oxford University Press.

Kesselring, Thomas. 2009. The Mind's Staircase Revised. In The Cambridge Companion to Piaget, ed. Ulrich Mueller, Jeremy I. M. Carpendale, and Leslie Smith, 372-399. New York: Cambridge University Press.

Kitchener, Richard F. 1996. Jean Piaget: the Unknown Sociologist? In Critical Readings on Piaget, ed. Leslie Smith, 28-50. London; New York: Routledge.

Kitchener, Richard F. 2004. Piaget's Social Epistemology. In Social Interaction and the Development of Knowledge, ed. Jeremy I. M. Carpendale and Ulrich Mueller, 45-66. Mahwah, NJ US: Lawrence Erlbaum Associates Publishers.

Kitchener, Richard F. 2009. On the Concept(s) of the Social in Piaget. In The Cambridge Companion to Piaget, ed. Ulrich Müller, Jeremy I. M. Carpendale, and Leslie Smith, 110-131. New York: Cambridge University Press.

Kuhn, Thomas. 1960. The Structure of Scientific Revolutions.

Kusch, Martin. 2006. Psychologism. Continuum Encyclopedia of British Philosophy.

Kusch, Martin. 2015a. Psychologism. In The Stanford Encyclopedia of Philosophy, ed. Edward N. Zalta, Winter 2015. Metaphysics Research Lab, Stanford University.

Kusch, Martin. 2015b. Psychologism, History of. Edited by James D. Wright. International Encyclopedia of the Social \& Behavioral Sciences. Oxford: Elsevier. https://doi.org/10.1016/B978-0-08-097086-8.03139-1.

Lammenranta, Markus. 2018. Epistemic Circularity. Internet Encyclopedia of Philosophy. https://iep.utm.edu/ep-circ/. Accessed December 16. 
Lloyd, Geoffrey E. R. 2007. Cognitive Variations: Reflections on the Unity and Diversity of the Human Mind. Oxford: Oxford Scholarship Online.

Lloyd, Geoffrey E. R. 2010. History and Human Nature: Cross-Cultural Universals and Cultural Relativities. Interdisciplinary Science Reviews 35: 201-214. https://doi.org/10.1179/030801810X12723585301318.

Lockhart, Thomas. 2016. Frege on Anti-Psychologism and the Role of Logic in Thinking. Theoria: A Swedish Journal of Philosophy 82: 302-328. https://doi.org/10.1111/theo.12101.

Martin, Ben. 2020. Identifying Logical Evidence. Synthese. Springer. https://doi.org/10.1007/s11229-020-02618-y.

Martin, Ben, and Ole Thomassen Hjortland. 2021. Evidence in Logic. In The Routledge Handbook of the Philosophy of Evidence, ed. Maria Lasonen-Aarnio and Clayton Littlejohn, Preprint. Routledge Handbooks in Philosophy. https://www.academia.edu/42231700/Evidence_in_logic. Accessed 10/6/2020: Routledge.

Mohanty, J. N. 1997. The Concept of "Psychologism" in Frege and Husserl. Philosophy \& Rhetoric 30: 271-290.

Overton, Willis, and Judith Newman. 1982. Cognitive Development: A CompetenceActivation/Utilization Approach. In Review of Human Development, ed. T. M. Field, A. Huston, H. C. Quay, L. Troll, and G. E. Finley, 217-240. New York: John Wiley and Son, Inc.

Pelletier, Francis J., Renée Elio, and Philip Hanson. 2008. Is Logic all in our Heads? From Naturalism to Psychologism. Studia Logica 88: 3. https://doi.org/10.1007/s11225008-9098-5.

Piaget, Jean. 1950a. Introduction à l'épistémologie génétique. (I) La pensée mathématique. Electronic version from Fondation Jean Piaget pour recherches psychologiques et épistémologiques. Pagination according to 1st edition 1950. Vol. 1. 3 vols. Paris: Presses Universitaires de France.

Piaget, Jean. 1950b. Introduction à l'épistémologie génétique. (III) La pensée biologique. La pensée psychologique. La pensée sociologique. Electronic version from Fondation Jean Piaget pour recherches psychologiques et épistémologiques. Pagination according to 1st edition 1950. Vol. 3. 3 vols. Paris: Presses Universitaires de France.

Piaget, Jean. 1952. The Origins of Intelligence in Children. Translated by Margaret Cook. New York: International Universities Press Inc.

Piaget, Jean. 1957. Logic and Psychology. Translated by W. Mays and F. Whitehead. New York: Basic Books Inc.

Piaget, Jean. 1970. Structuralism. Translated by Chaninah Maschler. New York: Basic Books Inc.

Piaget, Jean. 1971a. Genetic Epistemology. Translated by Eleanor Duckworth. Woodbridge Lectures 8. New York: W. W. Norton and Company Inc.

Piaget, Jean. 1971b. Biology and Knowledge: An Essay on the Relations Between Organic Regulations and Cognitive Processes. Translated by Beatrix Walsh. Chicago; London: University of Chicago Press.

Piaget, Jean. 1977a. Logic and Psychology. In The Essential Piaget, ed. Howard E. Gruber and J. Jacques Vonèche, 445-477. New York: Basic Books, Inc.

Piaget, Jean. 1977b. The Stages of Intellectual Development in Childhood and Adolescence. In The Essential Piaget, ed. Howard E. Guber and J. Jacques Vonèche, tran. H. E. Gruber, 814-819. New York: Basic Books, Inc. 
Piaget, Jean. 1977c. Phenocopy in Biology and the Psychological Development of Knowledge. In The Essential Piaget, ed. H. E. Gruber and J. Jacques Vonèche, 803813. New York: Basic Books.

Piaget, Jean. 2001. The Psychology of Intelligence. Translated by Malcolm Piercy and D. E. Berlyne. Routledge Classics. London; New York: Routledge.

Piaget, Jean, and Evert W. Beth. 1966. Mathematical Epistemology and Psychology. Translated by W. Mays. Softcover reprint of hardcover 1st edition. Vol. 12. Synthese Library. Dordrecht, Holland: Springer Netherlands.

Piaget, Jean, and Jean-Blaise Grize. 1972. Essai de logique opératoire. 2e éd. du Traité de logique, essai de logistique opératoire (1949). Vol. 15. Collection Sciences Du Comportement. Paris: Dunod.

Priest, Graham. 2016. Logical Disputes and the A Priori. Principios: Revista de Filosofia 23. Universidade Federal do Rio Grande do Norte: 29-57.

Quine, Willard Van Orman. 1966. The Ways of Paradox. In The Ways of Paradox and Other Essays, 3-20. New York: Random House.

Read, Stephen. 1995. Thinking About Logic: An Introduction to the Philosophy of Logic. New York: Oxford University Press.

Restall, Greg. 2006. Logic. An Introduction. e-book. Fundamentals of Philosophy. London; New York: Routledge.

Restall, Greg, and Jeffery C. Beall. 2000. Logical pluralism. Australasian journal of philosophy 78. Taylor \& Francis: 475-493. https://doi.org/10.1080/00048400012349751.

Restall, Greg, and Jeffery C. Beall. 2001. Defending Logical Pluralism. In Proceedings of the 1999 Conference of the Society of Exact Philosophy, 1-22. Stanmore: Hermes Science Publishers.

Russell, Gillian. 2019. Logical Pluralism. In The Stanford Encyclopedia of Philosophy, ed. Edward N. Zalta, Summer 2019. Metaphysics Research Lab, Stanford University.

Rutherford, D. E. 1966. Introduction to Lattice Theory. Reprint. University Mathematical Monographs. Edinburgh; London: Oliver and Boyd Ltd.

Seltman, Muriel, and Peter Seltman. 1985. Piaget's Logic: A Critique of Genetic Epistemology. London: George Allen \& Unwin.

Shapin, Steven. 1982. The History of Science and Its Sociological Reconstruction. History of Science 20: 157-211. https://doi.org/10.1177/007327538202000301.

Shapin, Steven. 2008. The Scientific Revolution. Chicago; London: University of Chicago Press.

Shapiro, Stewart. 2000. Thinking about Mathematics: The Philosophy of Mathematics. New York: Oxford University Press.

Smith, Leslie. 1987. A Constructivist Interpretation of Formal Operations. Human Development 30: 341-354. https://doi.org/10.1159/000273192.

Smith, Leslie, Ulrich Mueller, and Jeremy I. M. Carpendale. 2009. Introduction. Overview. In The Cambridge Companion to Piaget, ed. Leslie Smith, Ulrich Mueller, and Jeremy I. M. Carpendale, 1-44. New York: Cambridge University Press.

Sober, Elliott. 1978. Psychologism*. Journal for the Theory of Social Behaviour 8: 165-191. https://doi.org/10.1111/j.1468-5914.1978.tb00398.x.

Stenning, Keith, and Michiel van Lambalgen. 2008. Human Reasoning and Cognitive Science. Cambridge Massachusetts; London England: MIT Press.

Urbanski, Mariusz. 2011. Logic and Cognition: Two Faces of Psychologism. Logic and Logical Philosophy 20: 175-185. https://doi.org/10.12775/LLP.2011.009.

Wigner, Eugene. 1960. The Unreasonable Effectiveness of Mathematics in the Natural Sciences. Communications in Pure and Applied Mathematics 13. 
